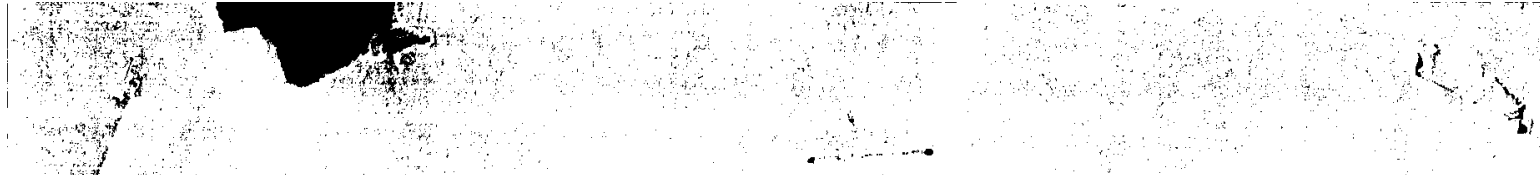

NASACONTRACTOR REPOR T
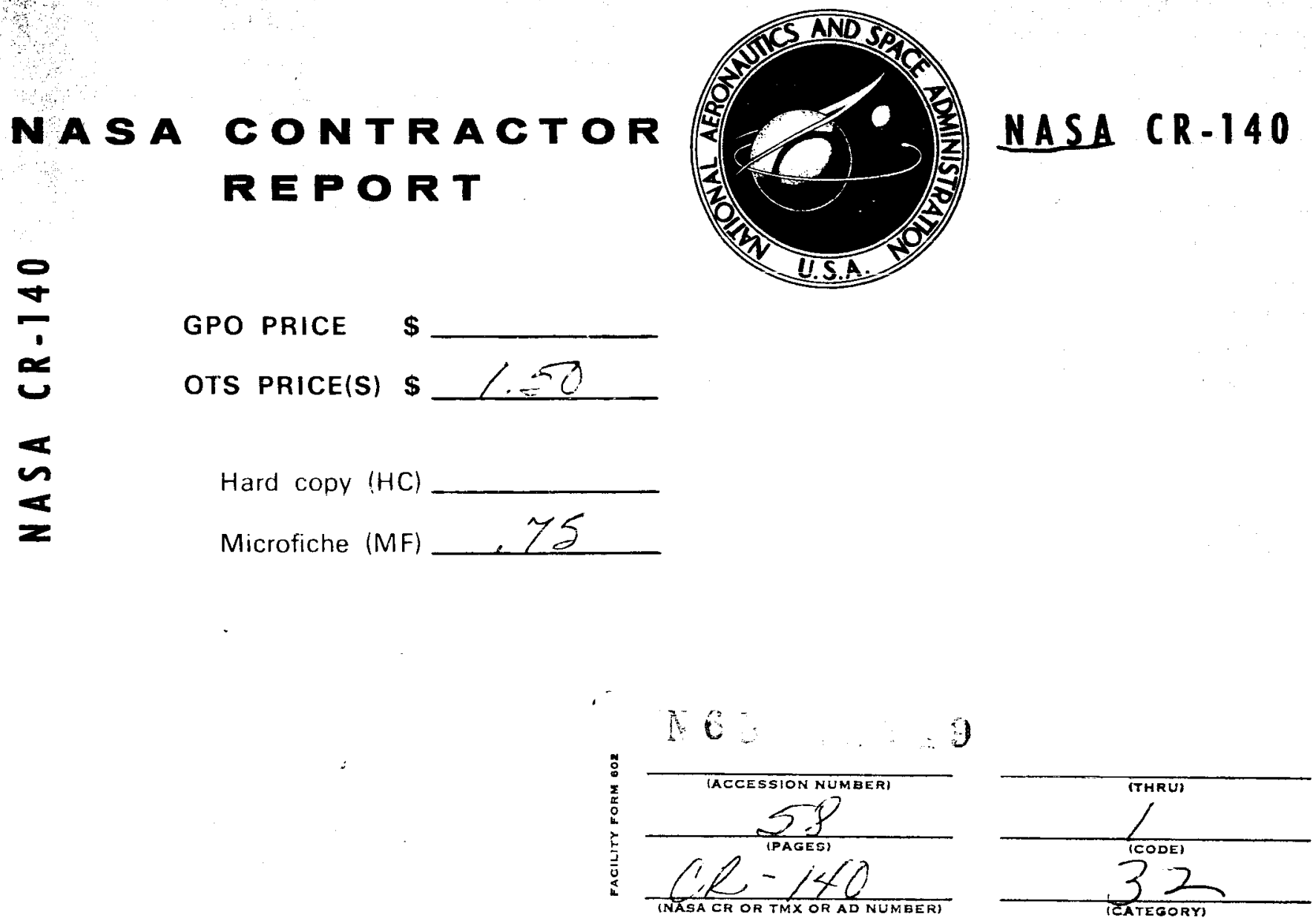

\title{
FRACTURE TESTING OF WELDMENTS
}

by J. A. Kies, H. L. Smith,

H. E. Romine, and H. Bernstein

Prepared by

NAVAL RESEARCH LABORATORY

Washington D. C.

for

National aeronautics and SPACE administration - WaShINGTON, D. C. - DECEMBER 1964 


\section{NASA CR-140}

FRACTURE TESTING OF WELDMENTS

By J. A. Kies, H. L. Smith, H. E. Romine, and H. Bernstein

Distribution of this report is provided in the interest of information exchange. Responsibility for the contents resides in the author or organization that prepared it.

Prepared by

NAVAL RESEARCH LABORATORY

Washington, D. C.

for

\section{NATIONAL AERONAUTICS AND SPACE ADMINISTRATION}

For sale by the Office of Technical Services, Department of Commerce, Washington, D.C. 20230 .. Price $\$ 1.50$ 
FRACTURE TESTING OF WELDMENTS

by

J. A. Kies*, H. L. Smith*, H. E. Romine**, and H. Bernstein***

Synopsis

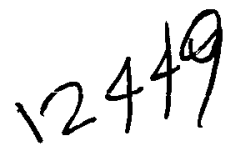

A new and improved apparatus has been designed and built for three point loading of bend bars. A new formula for $\mathrm{K}_{\mathrm{Ic}}$ independent of Young's modulus has been derived which fits experimental calibrations and calculations by B. Gross with satisfactory accuracy. A formula is provided by which the requirements for specimen size and notch depth can be calculated for measuring $\mathrm{K}_{\mathrm{Ic}}$ for a given yield strength of material. A number of comparisons are shown for the effect of rolling direction on $\mathrm{K}_{\mathrm{Ic}}$ for base plate and for several different kinds of welding. The effect of notch position on $\mathrm{K}_{\mathrm{Ic}}$ is shown. The slow bend test has advantages of adaptability and simplicity for the purpose at hand.

It seems noteworthy that the effect of directionality on $\mathrm{K}_{\mathrm{Ic}}$ in the base plate is in the same direction but magnified in tests of the welds in the $250 \mathrm{Ksi}$ yield strength grade. For some welding procedures the $\mathrm{K}_{\mathrm{Ic}}$ for some positions in welds was better than for the base plate with no deficiency of hardness. Significance tests were applied to the differences between average values of $\mathrm{K}_{\mathrm{Ic}} \cdot$ From the $\mathrm{K}_{\mathrm{Ic}}$ numbers listed one may calculate the larges tolerable surface crack corresponding to a given stress applied. The center of the weld presents the lowest toughness of any position.

*U. S. Naval Research Laboratory, Washington, D. C. 20390 **U. S. Naval Weapons Laboratory, Dahlgren, Virginia

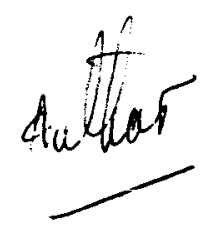
***Special Projects Office, BuWeps, Navy Dept., Washington, D.C. 


\title{
TABLE CONTENTS
}

\author{
Synopsis $\quad$ iii \\ Introduction - 1 \\ The Bend Specimen and Testing Fixtures 2 \\ Formulas and Calibration 2 \\ Plastic Zone Limitations $\quad 6$ \\ Demonstration of Linearity between $\mathrm{K}_{\mathrm{Ic}}$ and. Nominal
Fiber Stress \\ Limitations on Specimen Size and Notch Depth 7 \\ Comparison of Plane Strain Fracture Toughness by the \\ Slow Bend Test and by the Single Edge Notch Test 8 \\ Material and $K_{I c}$ Test Results for Base Plate 10 \\ $\begin{array}{ll}\text { Tungsten Inert Gas Welds } & 15\end{array}$ \\ Metal Inert Gas Welds 19 \\ Short Arc Welds $\quad 21$ \\ Surmary of $K_{\text {Ic }}$ Test Results 23 \\ $\begin{array}{ll}\text { Conclusions } & 27\end{array}$ \\ $\begin{array}{ll}\text { Acknowledgements } & 29\end{array}$ \\ $\begin{array}{ll}\text { References } & 30\end{array}$ \\ List of Figures $\quad 31$ \\ APPENDIX \\ Failure Analysis Example - Weld Flaw 49 \\ Cholce of Specimen Type ( 3 point bend test) 53 \\ Use of $\mathrm{K}$ Values Computed from an Equation 54
}


FRACTURE TESTING OF WELDMENTS

by

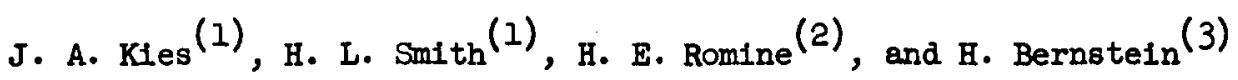

\section{Introduction}

Techniques for measuring the fracture toughness of weldments are not unlque or different from those for testing base plate except for simple considerations of adequate sampling and for studying metallurgical variables not present in the base plate. In this investigation use of $\mathrm{Ic}$ (or $\mathrm{K}_{\mathrm{Ic}}$ ) toughness numbers was helpful because, from current evidence, these numbers do not vary slgaiflcantly with specimen geometry. Thus the specimens could be efficiently planned from an expense viewpolnt. The present paper contains a description of a bend test procedure and neglects others only because our immediate concern is with steels for large solid propellant booster rockets in which the yield strength and the plate thicknesses are both high enough to make the use of bend tests convenfent. A list of the detailed reasons for choosing the 3 point loading bend test for the immediate purposes is given in the Appendix. For other applications other tests might be preferred. In choosing a specimen for a given task in measuring fracture toughness, a few simple rules should be observed as follows:

(a) The plastic zone size at critical load should be small compared with the crack depth and with the unbroken ligament.

(b) The computed nominal stress disregarding stress concentration factor should not exceed 1.1 times the nominal tensile yield strength.

(1) U. S. Naval Research Laboratory, Washington, D. C. 20390

(2) U. S. Naval Weapons Laboratory, Dahlgren, Virginia

(3) Special Projects Office, BuWeps, Navy Dept., Washington, D. C. 
(c) The machined notch should be terminated or extended by a real crack, most conveniently a fatigue crack.

(d) Testing arrangements should provide reproducible load deflection relations not disturbed by variable warpage in the specimen or insecure seating of the test fixture.

(e) A closed formula for $\mathrm{K}$ is highly desirable.

The Bend Specimen and Testing Fixtures

The bend specimen chosen for convenience in testing the plate is shown in Fig. 1. The test fixturing was especially deslgned to provide selfalignment and security from tilting durling load application. Figure 2 shows an assembly of specimen and fixture in the testing machine. Further detalls are to be found in Ref. (1)

In order to satisfy testing condition (d) above, a considerable effort was expended to provide a stable fixture easily lending itself to alignment and proper centering. Details of parts for the bend test apparatus are shown in Fig. 3 and sliding guldes for axially centering of the test bar are shown in FIg. 4.

Special attachments were made for use in fatiguing the notched bars so as to introduce a real crack. Figure 5 shows two assembly views of the fatigue apparatus and the test specimen. Figure 6 shows the construction of the spectal lever arm used for gripping the specimen.

Formulas and Calibration

In general if we can measure loads and deflectlons with sufficlent accuracy we can write for $P$ total load and A total crack area:

$$
g=\frac{P^{2}}{2} \frac{d(l / M)}{d A}
$$


where $1 / M$ is the compliance such that the elastic deflection $\delta$ is

$$
\delta=\frac{\mathrm{P}}{\mathrm{M}}
$$

Here we wish to consider bend bars of width $B$ and depth $D$. Then

$$
\theta=\frac{P^{2}}{2} \frac{\mathrm{d}(\mathrm{l} / \mathrm{M})}{\mathrm{B} \mathrm{d} \mathrm{a}} \text {, }
$$

where "a" is crack depth. If we choose to normalize with respect to plate thickness, we can write

$$
\theta=\frac{1}{2}\left(\frac{P}{B}\right)^{2} \frac{d(B / M)}{d a}
$$

Mast has postulated (Ref. 2) that for the Irwin factors a a d \% (strain energy release rates) acting independently on a crack and due to tensile and bending loads, the total is

$$
g=g_{p}+g_{m}
$$

In this case the total $K$ or stress intensity factor is not obtained by stress analysis but is given by

$$
K_{I}^{2}=\frac{E}{\left(1-\nu^{2}\right)}\left(\mathscr{E}_{I p}+\theta_{I m}\right)
$$

for plain strain. From the experimental point of view the derivatives of the compliance with respect to crack size would have to be independent for Eq. (2) to be correct. In case these are not independent then the total stress due to all loads would be obtained and the resulting total $\mathrm{K}$ or stress intensity factor determined accordingly. There would be no point in determining $K_{p}$ and $K_{m}$ separately. If $\&_{p}$ and $\&_{m}$ are not independent then $K_{p}$ and $K_{m}$ would have no usefulness as separate quantities.

In the present paper ${ }_{p}=0$ for the bend bars and there is no ambiguity. 
Mast (2) obtained approximate expressions for $K_{p}$ and $K_{m}$ for deep notches. His expression for $K_{m}$ is

$$
\mathrm{K}_{\mathrm{m}}=\frac{2 \mathrm{Pe}}{\mathrm{B} \sqrt{\pi} \ell^{3 / 2}}
$$

where $\mathrm{Pe}$ is the bending moment " $\mathrm{m}$ " on the unbroken ligament

$$
\mathrm{K}_{\mathrm{m}}=\frac{2 \mathrm{~m}}{\mathrm{~B} \sqrt{\pi} \ell^{3 / 2}}
$$

and

$$
\theta_{I}=\frac{\left(1-v^{2}\right)}{E} \frac{4 m^{2}}{B^{2} \pi l^{3}}
$$

For 3 point loading as used in our experiments

$$
m=\frac{P L}{4}
$$

and

$$
\begin{aligned}
& { }_{I}=\frac{1}{2}\left(\frac{P}{B}\right)^{2} \frac{\left(1-\nu^{2}\right) L^{2}}{2 E \pi l^{3}} \\
& \frac{d(B / M)}{d a}=\frac{\left(1-\nu^{2}\right) L^{2}}{2 E \pi l^{3}}
\end{aligned}
$$

However, simple dimensional considerations permit us to adapt this to shallow as well as deep notches by rewriting (5) as

$$
\begin{array}{rlrl}
\frac{\mathrm{d}(\mathrm{B} / \mathrm{M})}{\mathrm{da}} & =\frac{\left(1-v^{2}\right) \mathrm{L}^{2}}{2 \pi \mathrm{E}}\left[\frac{1}{l^{3}}-\frac{l^{3}}{(\mathrm{D} / 2)^{6}}\right] \\
\mathrm{a}+2 l & =\mathrm{D} & \mathrm{d} a & =-2 \mathrm{~d} l \\
\alpha & =2 l / \mathrm{D} & \mathrm{D} \mathrm{d} \alpha & =-\mathrm{da}
\end{array}
$$

The second term within the bracket of $\mathrm{Eq}$. (6) assures that $=0$ for $a=0$ without changing the dimensions of the bracket. The cholce of exponent 3 on $\ell^{3}$ was made to correspond with calibration data of Romine and the calculations of B. Gross (Ref. 4) except that for the Irwin callbration the second term, $\frac{l}{(D / 2)^{4}}$, a flrst power correction, provided a much better fit. D is the total beam depth. Equation (6) may be re- 
written as (7) with the insertion of a factor $S$ needed to include the 1.2 Irwin factor for surface notches (Ref. 3) and other effects.

$$
\frac{d(B / M)}{d a}=\frac{4 S\left(1-\nu^{2}\right) L^{2}}{\pi E D^{3}}\left[\frac{1}{\alpha^{3}}-\alpha^{3}\right]
$$

and

$$
\frac{B}{M}=\frac{2 S\left(1-v^{2}\right) L^{2}}{\pi E D^{2}}\left[\frac{1}{\alpha^{2}}+\frac{\alpha^{4}}{2}\right]+\text { Const. }
$$

Then

$$
H_{I}=2\left(\frac{P}{B}\right)^{2} \frac{S\left(1-v^{2}\right) L^{2}}{\pi E D^{3}}\left[\frac{1}{\alpha^{3}}-\alpha^{3}\right]
$$

Since

$$
\theta_{I}=\frac{1}{2}\left(\frac{P}{B}\right)^{2} \frac{d(B / M)}{d a}
$$

then for $L=2 L_{1}$ and $S=1.667$

$$
R=\frac{K_{I} D^{3 / 2}}{P / B L_{I}}=2.060\left\{\frac{1}{\alpha^{3}}-\alpha^{3}\right\}^{1 / 2}
$$

The selection of $S=1.667$ was done for the purpose of fltting the Romine and other calibration data as shown in Fig. 7. This figure also shows that Equation (10) fits the values of $R$ as calculated by B. Gross (Ref. 4) well within experimental uncertainties in calibrations. * Equation (10) is the same for symmetrical four point bending except that $L_{I}$ then is the distance between outer and next inner load points. We have no experimental data at present for checking Equation (10) for four point loading. In obtalning $R$ experimental for the Romine calibration bars $2-3$ and $2-6$ the values of $E=27 \times 10^{6}$ psi, $\nu=0.25$, $D=0.750$ inch, and $L_{1}=3$ inches were used. For purposes of entering the Romine data on Fig. 7 ,

$$
R=0.824 \sqrt{\frac{d(B / M)}{d a}} \times 10^{3},
$$

where $\frac{d(B / M)}{d a}$ was experimentally determined.

\footnotetext{
* Good agreement between Equation (10) and a corrected version of a formula by Beuchner ( 7 ) has also been reported in a private communication by $\mathrm{Mr}$. Carl Hartbower, Aerojet-General Corp.
} 
Plastic Zone Limitations

Thus far Equations $(9,10)$ for $\mathscr{G}_{I}$ and $K_{I}$ do not include plastic zone corrections. Introduction of this correction complicates the formula considerably and it is suggested that this is not necessary provided that the nominal fiber stress at the root of the notch is kept below 1.1 times the yleld stress. The estimated plane strain plastic zone size, $2 \mathrm{r}_{\mathrm{y}}$, when $\sigma_{\mathrm{nom}}=1.1 \sigma_{\mathrm{YS}}$ is about $0.04 "$. Use of the plasticity correction would at the extreme increase $\mathrm{K}$ by about $10 \%$.

Demonstration of Linearity between $K_{I c}$ and Nominal Fiber Stress

A demonstration of the necessary linearity between $K_{I c}$ (for flxed span and approximately fixed notch dimensions) and nominal fiber stress may be seen in Fig. 8a. These data points are for maraging steel bars from a heat different from that for the bulk of this report. Only specimens containing surface notches are shown. Ic values were computed using an equation based upon a compliance calibration. $K_{I c}$ values were then computed from the equation

$$
K_{I c}^{2}\left(1-\nu^{2}\right)=E{ }_{I c} \text {. }
$$

If one computes $K_{I c}$ using Equation (10) for these data points, the relationship between $K_{I c}$ and the load $P$ is:

$$
K_{I c}=27.95 \mathrm{P}
$$

If the load is converted to maximum fiber stress at the notch root, $s^{\prime}$, and. dividing by the yield strength of the material, the expression for $K_{I_{c}}$ becomes

$$
K_{\mathrm{Ic}}=93,175\left(\frac{\mathrm{s}^{\prime}}{\sigma_{\mathrm{YS}}}\right)
$$

The straight line through the origin representing this equation in Fig. $8 \mathrm{a}$ shows good agreement with Romine's results. Part of the scatter shown by the 
open squares may be expected on the basis of mlcrostructural variability in welds; however, the rest of the data shows the required linearity. Varlations in $S^{\prime} / \sigma_{Y S}$ for a given $K_{I c}$ value reflect varlations in notch depth. Variations-larger than $10 \mathrm{Ks} 1 \sqrt{\mathrm{In}}$. In the $K_{\mathrm{Ic}}$ values reflect real changes in toughness. Within a fixed type of material (base metal, for example) the $K_{I c}$ toughness variations are belleved to be due to delaminations. Romine's data for plate surface notched specimens range in notch depth only from 0.10 to 0.14 inches. Within this range no speclal correlation of $K_{I c}$ with notch depth was observed.

Limitations on Specimen Size and Notch Depth

In forecasting the required specimen size and notch depth, it is necessary to know in advance how high $K_{I c}$ will be.

Assuming that at the root of the notch the nominal fiber stress is

$$
\begin{aligned}
& \sigma_{\text {nom }}=\frac{\mathrm{m} \ell}{\mathrm{I}} \\
& \sigma_{\text {nom }}=3 \frac{\mathrm{PL} \mathrm{L}_{1}}{\mathrm{~B} \alpha^{2} \mathrm{D}^{2}}
\end{aligned}
$$

Then

$$
K_{I}=\sigma_{\text {nom }} \sqrt{D} 0.687\left\{\alpha-\alpha^{7}\right\}^{1 / 2}
$$

If the upper limit of validity is for $\sigma_{\text {nom }}=1.1 \sigma_{Y S}$

$$
K_{I_{11 m}}=0.756 \sigma_{Y S} \sqrt{D}\left\{\alpha-\alpha^{7}\right\}^{1 / 2}
$$

For the limiting case $K_{I_{c}}=K_{I c}$ lim

$$
\underset{l i m}{\Delta \varepsilon} \cong \frac{K_{I c l i m}^{2}}{4 \sqrt{2} \sigma_{Y S}^{2}}
$$


or

$$
\lim _{\mathrm{a}}=0.101 \mathrm{D}\left\{\alpha-\alpha^{7}\right\}
$$

$f_{2}(\alpha)=\left\{\alpha-\alpha^{7}\right\}$ has a maximum at $a / D=0.28$ or $\alpha=0.72$. Thus the most favorable notch depth ratio is about 0.28 . However, the term $\left(\alpha-\alpha^{7}\right)$ changes by only $0.2 \%$ in going from an a/D value of 0.25 to a value of 0.30 . So within this range of notch depth ratios one may simple use the equation

$$
K_{I}=0.540 \sigma_{\text {nom }} \sqrt{D}
$$

Comparison of Plane Strain Fracture Toughness by the Slow Bend Test and by the Single Edge Notch Test

Tests were made on $18 \mathrm{N1}$ (250,000 psi strength level) maraging steel plates from 3/4" thick, air melted stock. The bend tests were made with 3 point loading using $3 / 4 " \times 3 / 4 " \times 7.5^{\prime \prime}$ specimens while the single-edge-notch specimens were 3 " $x 12 " \times 0.75^{\prime \prime}$ in size loaded in tension with pin holes at W/2 position. Results are given in Table I (Ref. 5). The material used in this comparison was previously recelved from an outside source different from the one for which the bulk of the data are presented in this paper.

TABLE I

Comparison of Edge Notch Tear Tests with Bend Tests

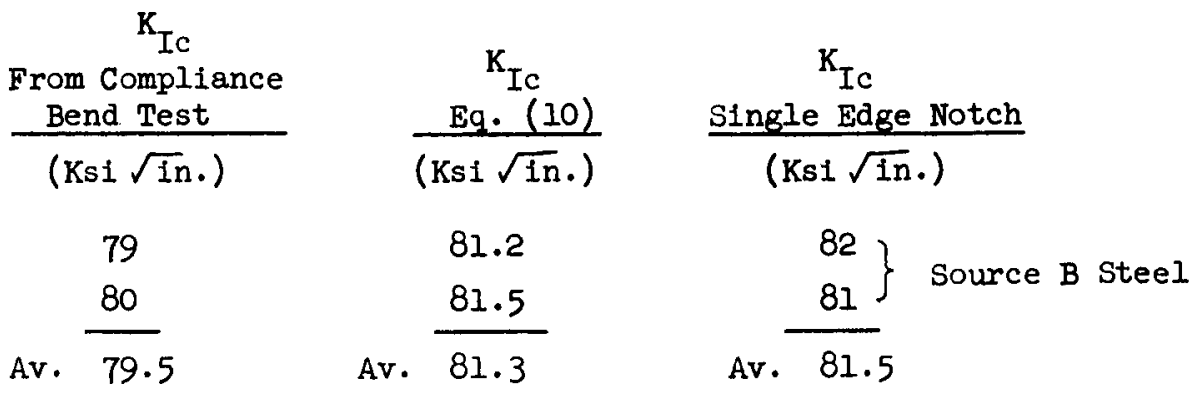


TABLE I (Cont.)

\begin{tabular}{|c|c|c|c|c|c|c|}
\hline $\begin{array}{l}\text { Bend Bar } \\
\text { Bar No. }\end{array}$ & or 11 & $\begin{array}{c}\mathrm{K}_{\mathrm{Ic}} \\
\mathrm{Eg} \cdot(10) \\
\end{array}$ & $\begin{array}{l}\text { Spec. No. } \\
\text { Edge Notch Tear }\end{array}$ & 1 or 11 & & $\mathrm{~K}_{\mathrm{Ic}}$ \\
\hline & te 1 & $\left(K_{s i} \sqrt{i n}\right)$ & & Plate 2 & \multicolumn{2}{|c|}{$\left(\right.$ Ksi $\left.V_{\text {in. }}\right)$} \\
\hline $1-31-2$ & $I$ & 67.5 & VII $B A-2$ & 1 & & 73.0 \\
\hline $1-31-3$ & $\perp$ & 67.2 & VII $B A-3$ & $\perp$ & & 72.0 \\
\hline $1-31-4$ & $\perp$ & 66.1 & VII $B A-4$ & 1 & & 69.0 \\
\hline \multirow[t]{2}{*}{$1-31-5$} & 1 & 68.8 & & & & \\
\hline & & 67.4 & & & \multirow[t]{2}{*}{ Av. } & 71.3 \\
\hline & ate 2 & & & Plate 1 & & \\
\hline $2-31-2$ & 11 & 68.8 & VII $A A-2$ & 11 & & 72.0 \\
\hline $2-31-3$ & 11 & 67.0 & VII $A A-3$ & 11 & & 75.0 \\
\hline $2-31-4$ & 11 & 68.5 & & & Av. & 73.5 \\
\hline $2-31-5$ & II & 68.3 & & & & \\
\hline & & Av. 68.1 & & & & \\
\hline
\end{tabular}

Earlier work by the U. S. Steel Corporation (Ref. 6) on 0.16" thick $18 \mathrm{Ni}$ maraging steel of the 280,000 psi yield strength level gave the results shown in Table II. The single edge notch specimens were loaded in tension with the pin holes at $\mathrm{w} / 3$ position. $\mathrm{K}_{\mathrm{Ic}}=\mathrm{E} \mathscr{8}_{\mathrm{Ic}} /\left(1-\nu^{2}\right)$ where $E=27 \times 10^{6}$ psi and $v=0.3$. The bend test values shown here are based on analytical results obtained by B. M. Wundt from work by Bueckner (Ref. 7).

\section{TABLE II}

Comparison of Edge Notch Tear Tests and Bend Tests

(U. S. Steel Co. Tests)

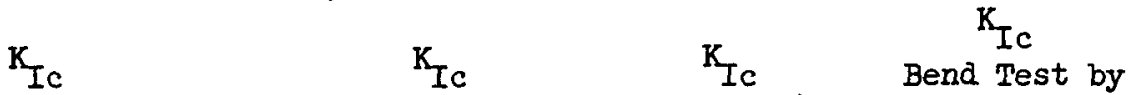

3" Wide Central-Notch Single Edge Notch Eq. (10) Bueckner Formula

\begin{tabular}{|c|c|c|c|}
\hline$(\operatorname{Ksi} \sqrt{\ln })$. & $(\mathrm{Ks} 1 \sqrt{\mathrm{In}} \cdot)$ & $(K s 1 \sqrt{\text { in. }})$ & $(K s i \sqrt{\ln })$. \\
\hline \multirow[t]{3}{*}{77.0} & 77.0 & 85.0 & 82.5 \\
\hline & 79.8 & 83.8 & 82.5 \\
\hline & 78.4 & 84.4 & 82.5 \\
\hline
\end{tabular}


It is tentatively concluded from Tables $I$ and II that $K_{\text {Ic }}$ obtained in bend tests using Equation (10) gives good agreement with single edge pop-In tests. Further testing is in progress.

Material and $K_{I_{c}}$ Test Results for 3/4-inch Thick Plate of 18 Percent Nickel Maraging Steel shown in Tables III et. seg.

Compositions and heat numbers are shown in Table III for materials tested and results shown in Tables IV to XIII inclusive.

TABLE III-a

Materials Compositions

Composition

C

Mn

$P$

$\mathrm{S}$

SI

$\mathrm{Ni}$

Mo

co

Ti

Al

$\mathrm{Cu}$
Plates

\begin{tabular}{cc}
\hline Heat X14636 & Heat X53013 \\
\cline { 1 - 2 } 0.03 & 0.02 \\
0.06 & 0.02 \\
0.005 & 0.006 \\
0.010 & 0.009 \\
0.10 & 0.04 \\
18.37 & 17.59 \\
4.70 & 4.80 \\
8.49 & 8.06 \\
0.42 & 0.49 \\
0.13 & 0.07 \\
& 0.12
\end{tabular}


TABLE III-b

Mechanical Properties of the Plates

Heat X14636 Heat X53013

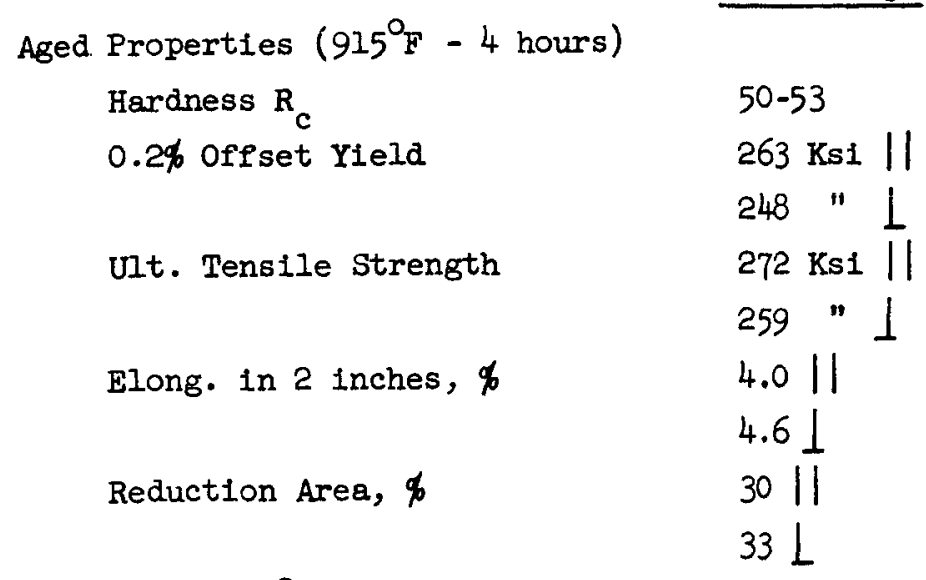

Annealed ( $1550^{\circ} \mathrm{F}-1$ hour)

Hardness

$32.8 \mathbf{R}_{\mathrm{c}}$

$32.3 \mathrm{R}_{\mathrm{c}}$

TABLE III-c

Weld Rod Chemistry

$\begin{array}{llll}\mathrm{C} & 0.02 \% & \mathrm{Mo} & 4.62 \% \\ \mathrm{Si} & 0.02 \% & \mathrm{Al} & 0.09 \% \\ \mathrm{Mn} & 0.03 \% & \mathrm{TI} & 0.45 \% \\ \mathrm{~S} & 0.005 \% & \mathrm{H}_{2} & 1.5 \mathrm{ppm} \\ \mathrm{P} & 0.004 \% & \mathrm{O}_{2} & 14.0 \mathrm{ppm} \\ \mathrm{NI} & 18.24 \% & \mathrm{~N}_{2} & 25.0 \mathrm{ppm} \\ \mathrm{Co} & 7.90 \% & & \end{array}$

Note: Identical weld rod chemistry for TIG, MIG, and Short Arc Welding. Weld rod drawn to different diameters. 


\section{Correspondence Between Plate and. Heat Numbers,}

Weld Method, and Rolling Direction

\begin{tabular}{|c|c|c|c|c|c|}
\hline \multirow{2}{*}{$\begin{array}{l}\text { NRL } \\
\text { Plate ìo. }\end{array}$} & \multirow{2}{*}{$\begin{array}{l}\text { Weld } \\
\text { Method }\end{array}$} & \multirow{2}{*}{$\begin{array}{l}\text { Plate No. } \\
\text { (U. S. Steel } \\
\text { Co.) } \\
\end{array}$} & \multirow{2}{*}{$\begin{array}{l}\text { Heat No. } \\
\text { (U. S. Steel } \\
\text { Co.) } \\
\end{array}$} & \multicolumn{2}{|c|}{$\begin{array}{c}\text { Rolling Direction } \\
\text { Orientation }\end{array}$} \\
\hline & & & & Weld Bead & Bar Length \\
\hline 1 & TIG & 42298 & $x 14636$ & $\perp$ & 11 \\
\hline 2 & TIG & 42298 & $x 14636$ & 11 & $\perp$ \\
\hline 5 & MIG & 42298 & $x 14636$ & $\perp$ & $\|$ \\
\hline 6 & MIG & 156872 & $\times 53013$ & 11 & $\perp$ \\
\hline 11 & Short Arc & 156872 & $\times 53013$ & $\perp$ & $\|$ \\
\hline
\end{tabular}

Detalls of the welding procedures are supplied by Excelco Developments Inc. and are included in the Appendix along with NRL chemical analyses of weld metal taken from test bars.

Table IV shows $K_{I c}$ values obtalned on base plate using bars cut perpendicular to and parallel with the rolling direction. Conditions are 3 point bending. $K_{I c}$ is computed from Equation (10) and visual notch depth.

It is noteworthy that all of the tests in Table IV were made with the notch on the plate surface so as to simulate expected cracking in rocket cases. This direction is conduclve to crack arrest by delamination or diversion of fracture path. The dependence of $\mathrm{K}_{\mathrm{Ic}}$ on direction of crack propagation has been previously investigated by Romine (Ref. 5). Average $K_{I c}$ for plate surface notches was reported as $83 \mathrm{Ks} 1 \sqrt{\mathrm{in}}$. versus $69 \mathrm{KsI} \sqrt{\mathrm{In}}$. for edgewise propagation in base bars cut in the rolling direction in the earlier tests. For bars cut transverse to the rolling direction the effect was in the same direction but less pronounced; average $K_{I c}$ values were 66 and $64 \mathrm{Ksi} \sqrt{\mathrm{in}}$. respectively for the same plate. Typical fracture appearances for bend bars in which the notches are on the plate surface and plate edge are shown in Figs. 9 and 10 for plates from two different sources not represented in Tables IV - XIII. It is clear that the orlentation of the notch has an influence on the toughness of the base plates. Simflar differences according to crack propagation direction are 1llustrated for NRL plate 2 in F1gs. 11 and 12. 
TABLE IV

NRI Plates 1 and 2

$K_{\text {Ic }}$ Values for Base Plate Equation (10) and Visual Notch Depth "a" Used

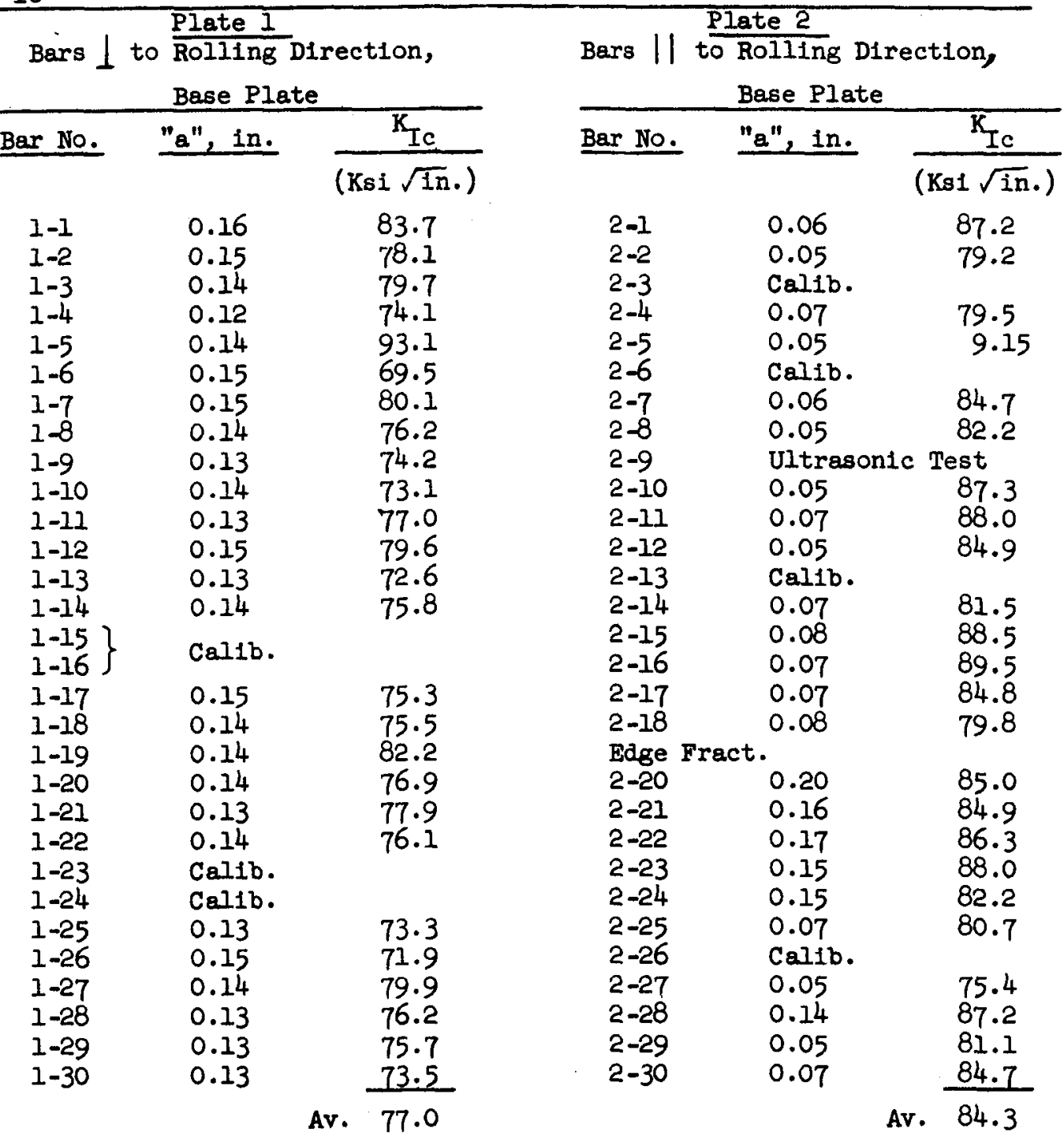


TABLE V

$\mathrm{K}_{\text {Ic }}$ Numbers for Notches in the Center of TIG Welds

Welds are run transverse to the bars.

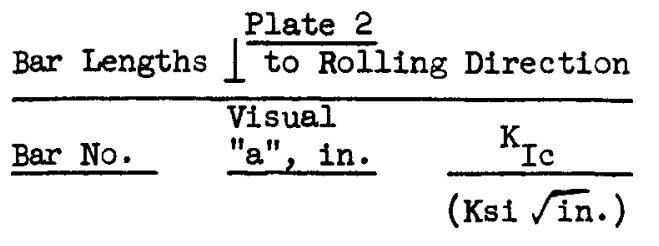

IV $\mathrm{BA}-1$

20.13

$3 \quad 0.16$

$4 \quad 0.15$

$5 \quad 0.17$

$6 \quad 0.18$

$7 \quad 0.14$

80.15

$9 \quad 0.14$

$10 \quad 0.14$

$11 \quad 0.16$

12

13

14

15

16

17

18
0.15

0.18

0.14

0.16

0.15

0.16

0.16
66.9

57.2

70.6

61.0

68.7

57.8

60.3

67.6

79.5

68.0

77.0

82.4

80.2

59.4

81.0

75.3

68.2

$72 \cdot 3$

Av. 69.6

c.v. $\quad 0.12$

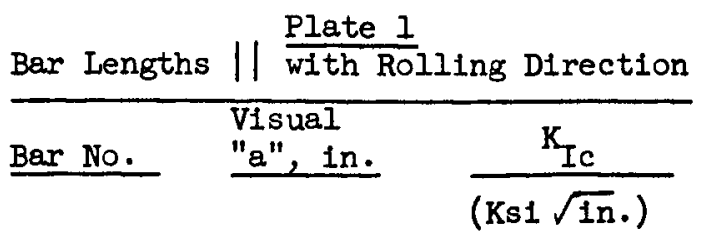

IV $A A-I$

0.15

88.8

80.1

87.5

91.2

103.1

93.3

113.8

90.3

69.8

74.5

60.3

85.7

74.2

80.9

75.9

64.1

91.0

17

0.16

0.18

$$
\begin{array}{cc}
\text { Av. } & 83.8 \\
\text { c.v. } & 0.15
\end{array}
$$

Note: The large difference between $K_{I C}$ for bars IV AA-7 and IV AA-1I was attributable to microstructure. Bar-7 was fine grained and Bar-ll coarse grained at the root of the starting crack. This will receive more future detalled study by metallography. 


\section{Tungsten Inert Gas Welds}

Tungsten inert gas welding was investigated. The typical sequence of passes is indicated by an etched cross section shown in FIg. 13. $K_{\text {Ic }}$ values for plates TIG welded are given in Tables $V$ to VIII. The orientation of the bars perpendicular and parallel with rolling direction is indicated. The weld beads were transverse to the bars and the position of the notch is coded as follows:

$$
\begin{aligned}
& \text { C.W. - center of the weld } \\
& \text { F.Z. - fusion zone where base plate is melted } \\
& \text { H.A.Z. - heat affected zone in the base plate } \\
& \text { D.B. - dark band just outside H.A.Z. }
\end{aligned}
$$

The typical TIG weld lay-up and the positions of the notches are shown in Fig. 13a. The weld bead lay-ups for MIG and short arc welds are shown on etched bend bars in Figs. $13 \mathrm{~b}$ and $13 \mathrm{c}$ respectively.

The $K_{I C}$ results for the fusion zone or edge of the fusion zone in TIG veld; are shown in Table VI. Each specimen was etched on the sides prior to testing to verify the position of the bottom of the fatigue crack below the notch. Although some uncertainty remained, the position code was assigned in accordance with the etched appearance not always the same as the original intended position. The code letters assigned were in accordance with Fig. 14. The notch position assignments were the best that could be done on this basis and within the authors' ability to distinguish etched structures with the usual visual aids. In order to get valid $K_{I c}$ numbers, say for F.Z. or H.A.Z., it is not necessary for the propagation to proceed more than a very small distance in the specified structure. The load at initiation of the fracture is hopefully the only load recorded. The pop-in must produce an offset of at least $1 / 16-$ inch on the record which corresponds to $0.0004-1$ nch deflection of the specimen. This corresponds to an increment in crack depth of $0.004-1$ nch. The records indicate that the load at pop-in is never appreciably different from that after this amount of pop-in. 
The center-of-weld toughness was found to be less than that at any other position.

The microstructural details existing at the tips of the cracks were not investigated. This will be the subject of a future investigation aimed at offering guldance for future materials improvement.

\section{TABLE VI}

Kc for the Fusion Zone TIG Welds

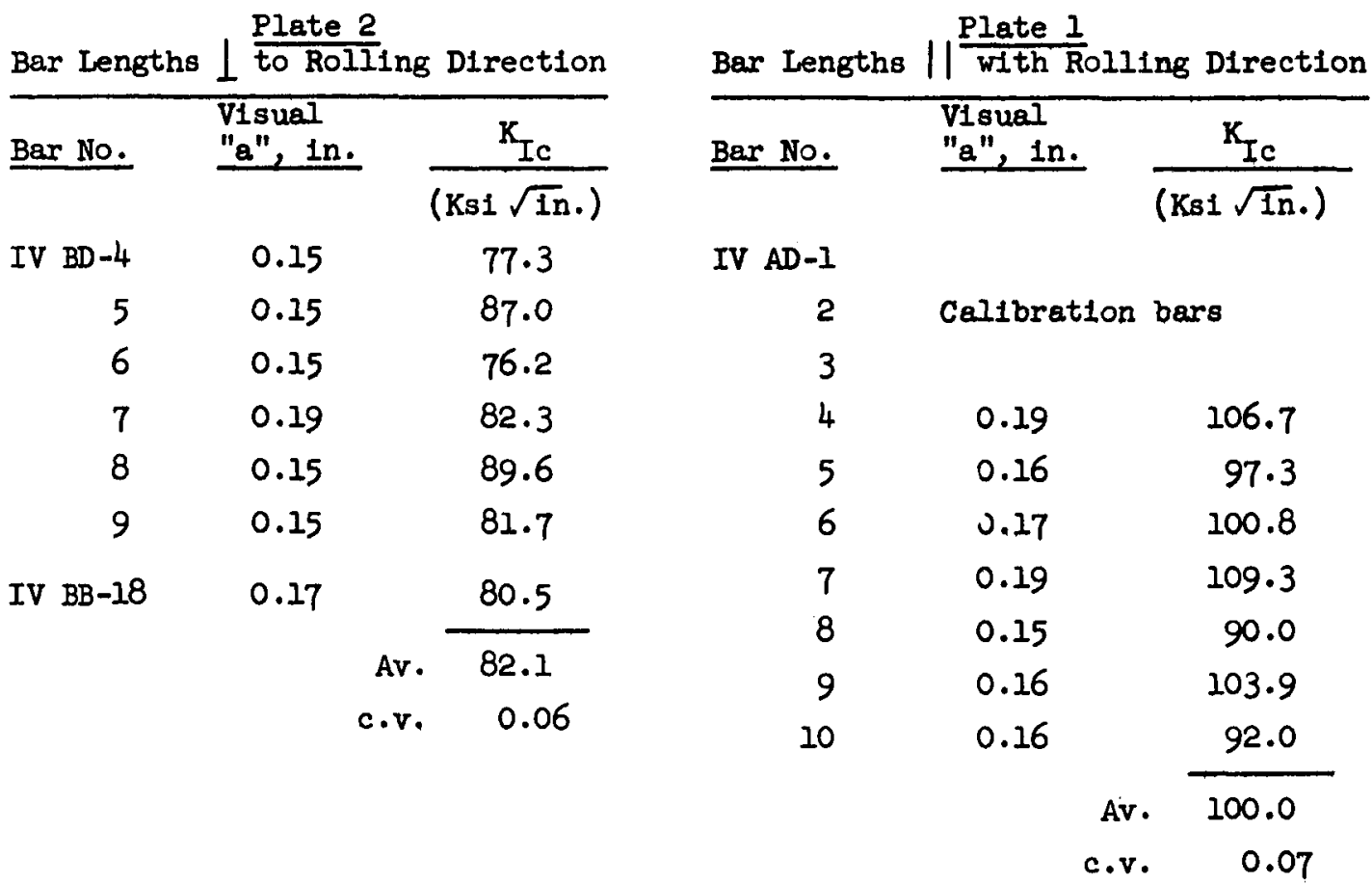


The K $K_{\text {Ic }}$ test results for the heat affected zone (H.A.Z.) are shown In Table VII for TIG welds.

\section{TABLE VII}

$\mathrm{K}_{\mathrm{Ic}}$ for the Heat Affected Zone TIG Welds (H.A.Z.)

\begin{tabular}{|c|c|c|c|c|c|}
\hline Bar Lengths & $1 \frac{\text { Plate } 2}{\text { to RoII }}$ & Direction & Bar Lengths & $\frac{\text { Plate }}{\text { with F }}$ & ing Direction \\
\hline Ber No. & $\begin{array}{l}\text { Visual } \\
\text { "a", in. }\end{array}$ & $\mathrm{K}_{\mathrm{IC}_{c}}$ & Bar No. & $\begin{array}{l}\text { Visual } \\
\text { "a", in. }\end{array}$ & $\mathrm{K}_{\mathrm{Ic}}$ \\
\hline & & $\left(K_{s 1} \sqrt{\ln }\right)$ & & & (Ksis $\sqrt{\text { in }}$ ) \\
\hline IV $B B-8$ & 0.18 & 87.6 & IV $A B-9$ & 0.14 & 101.9 \\
\hline 9 & 0.18 & 66.8 & 10 & 0.14 & 88.6 \\
\hline 10 & 0.17 & 71.1 & 11 & 0.14 & 82.3 \\
\hline 11 & 0.15 & 59.5 & 12 & 0.14 & $82 \cdot 3$ \\
\hline 12 & 0.19 & 73.2 & 13 & 0.15 & 104.0 \\
\hline 13 & 0.14 & 90.0 & 14 & 0.14 & 102.7 \\
\hline 14 & 0.19 & 60.7 & 27 & 0.16 & 103.1 \\
\hline 15 & 0.15 & 76.3 & 18 & 0.16 & 91.6 \\
\hline 16 & 0.15 & 85.8 & & & \\
\hline 17 & 0.17 & 75.9 & & & \\
\hline & & ง. 74.7 & & & 94.6 \\
\hline & & . $\quad 0.14$ & & & 0.10 \\
\hline
\end{tabular}


The KIc test results for dark band at the junction of the base plate and heat affected zone are given in Table VIII for TIG welds.

\section{TABLE VIII}

$K$ for the Dark Band at the Junction of Base If late and Heat Affected Zone TIG Welds (D.B.)

Plate 2

Bar Lengths $\perp$ to Rolling Direction Bar Lengths || with Rolling Direction

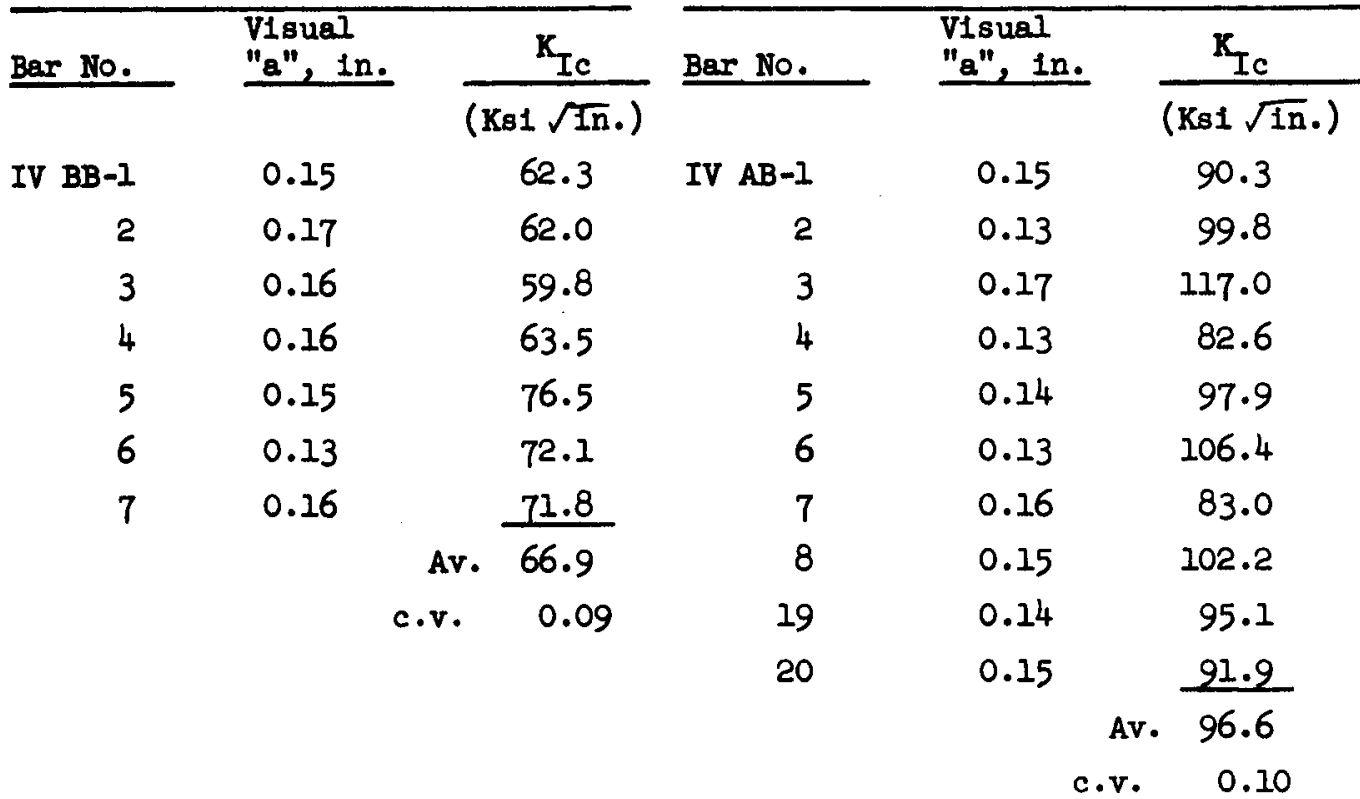




\section{Metal Inert Gas Welds}

A photograph showing the etched cross section of a typlcal MIG weld is shown as Fig. 13b. Toughness numbers for such welds notched in the center of the weld are given in Table IX.

\section{TABLE IX}

$K_{\text {Ic }}$ for MIG Welds Notched in the Center of the Weld (C.W.)

\begin{tabular}{|c|c|c|c|c|c|c|c|c|}
\hline Bar & - Lengths & $1 \frac{\text { NRL Pla }}{\text { to Roll }}$ & $\frac{\text { e } 6}{n g \text { Direction }}$ & Bar & Length & $\frac{\text { NRL P }}{\text { with I }}$ & $\frac{\text { late }}{\text { Rolli }}$ & $\frac{5}{\text { ing Directior }}$ \\
\hline Bar & No. & $\begin{array}{l}\text { Visual } \\
\text { "a", in. }\end{array}$ & $\mathrm{K}_{\mathrm{Ic}}$ & Ber & No. & $\begin{array}{l}\text { Visual } \\
\text { "a", in. }\end{array}$ & & $\mathrm{K}_{\mathrm{Ic}}$ \\
\hline & & & $(\mathrm{Ksi} \sqrt{\mathrm{in} .})$ & & & & & (Ksi $\sqrt{\text { in. }})$ \\
\hline II & $\mathrm{BA}-\mathrm{I}$ & 0.15 & 70.2 & II & $A A-1$ & 0.14 & & 72.0 \\
\hline & 2 & 0.15 & 74.1 & & 4 & 0.13 & & 71.8 \\
\hline & 3 & 0.15 & 62.6 & & 6 & 0.13 & & 70.7 \\
\hline & 4 & 0.20 & 54.4 & & 7 & 0.14 & & 64.4 \\
\hline & 5 & 0.14 & 70.5 & & 8 & 0.13 & & 85.9 \\
\hline & 6 & 0.15 & 63.2 & & 10 & 0.12 & & 71.4 \\
\hline & 7 & 0.14 & 70.6 & & 11 & 0.12 & & 75.8 \\
\hline & 8 & 0.14 & 71.8 & & 13 & 0.15 & & 80.1 \\
\hline & 9 & 0.15 & 67.0 & & 15 & 0.14 & & 60.4 \\
\hline & 10 & 0.13 & 87.3 & & 16 & 0.13 & & 71.4 \\
\hline & 11 & 0.14 & 74.1 & & 17 & 0.13 & & 102.7 \\
\hline & 12 & 0.13 & 86.9 & & 18 & 0.14 & & 105.7 \\
\hline & 13 & 0.15 & 84.4 & & & & Av. & $77 \cdot 7$ \\
\hline & 14 & 0.14 & 83.0 & & & & & \\
\hline & 15 & 0.15 & 81.8 & & & & & \\
\hline & 16 & 0.14 & 78.8 & & & & & \\
\hline & 17 & 0.13 & 85.3 & & & & & \\
\hline & 18 & 0.14 & $74 \cdot 3$ & & & & & \\
\hline & 19 & 0.13 & 71.4 & & & & & \\
\hline & & & Ave. 74.3 & & & & & \\
\hline & & c. & 0.12 & & & & & \\
\hline
\end{tabular}


$K_{\text {Ic }}$ results for notches terminating in the heat affected zone of MIG welds are shown in Table $X$.

TABLE $X$

Toughness in the Heat Affected Zone MIG Welds (H.A.Z.)

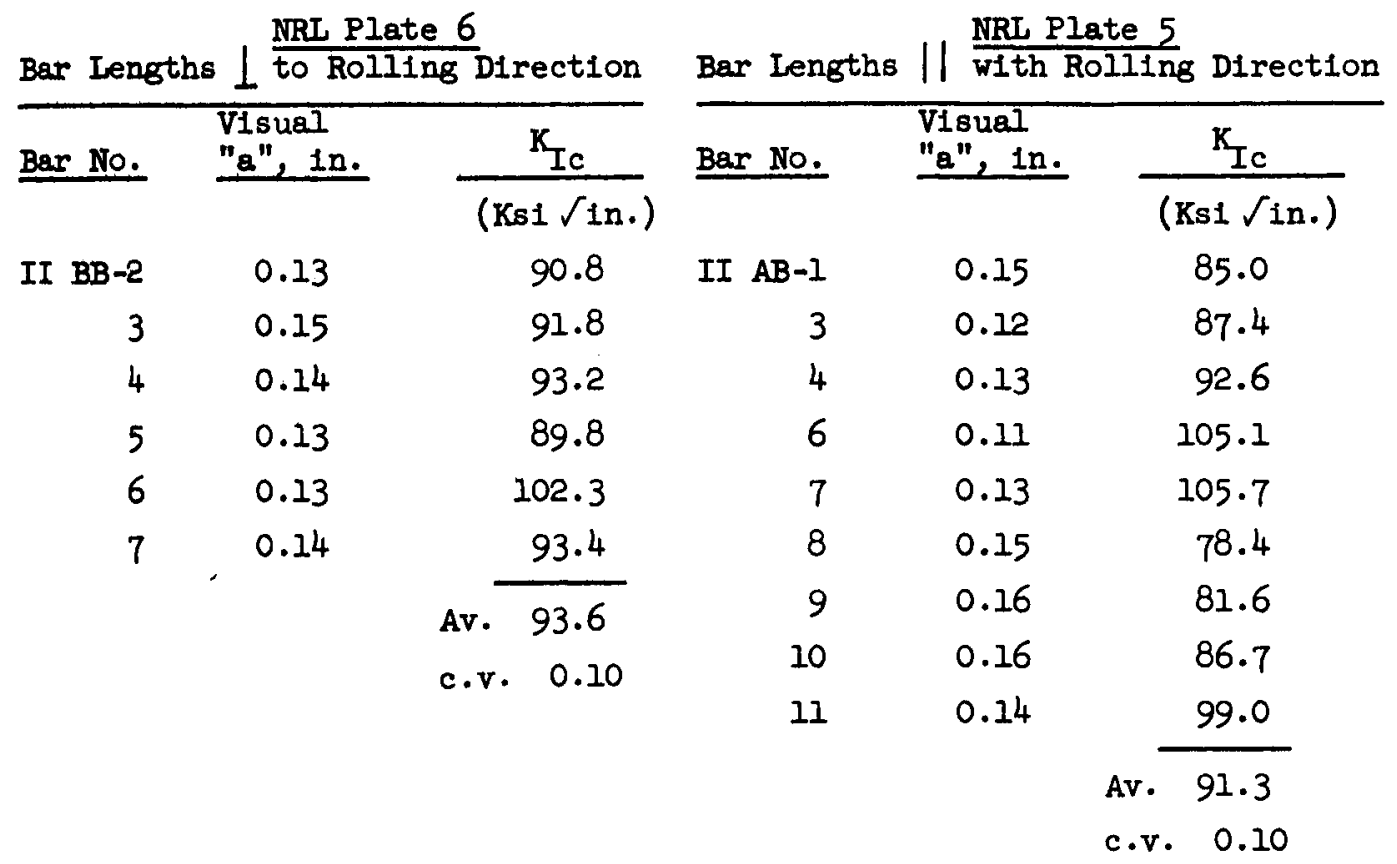

$K_{\text {Ic }}$ test results for notches terminating in the center of the weld and heat affected zones for Short Arc Welds are shown in Tables XI and XII respectively. 
TABLE XI

Short Arc Weld Toughness Data for Center of the Weld.

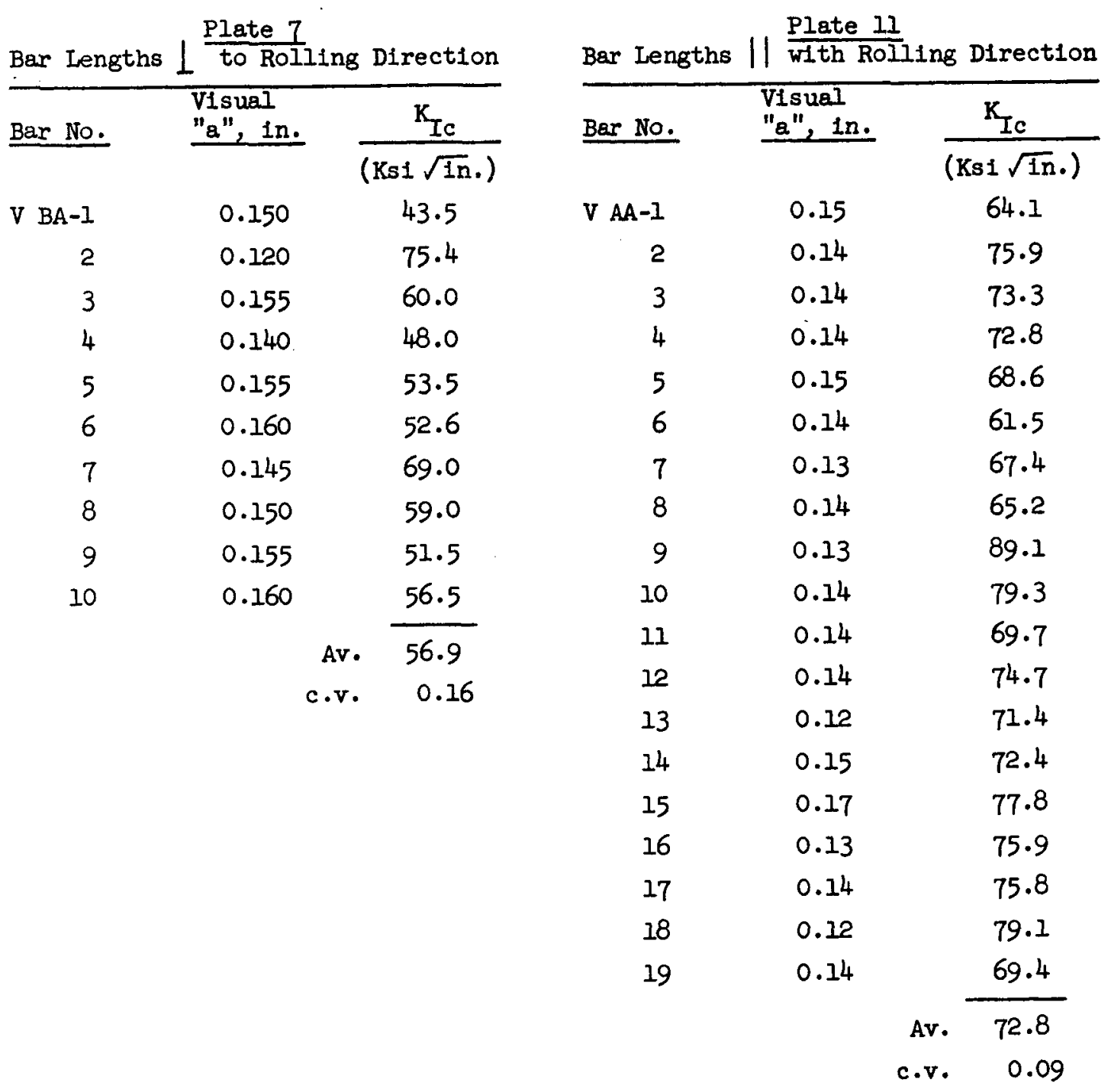


TABLE XII

$K_{\text {Ic }}$ Test Results for Notches Terminating

in the Heat Affected Zone, Short Arc Welds

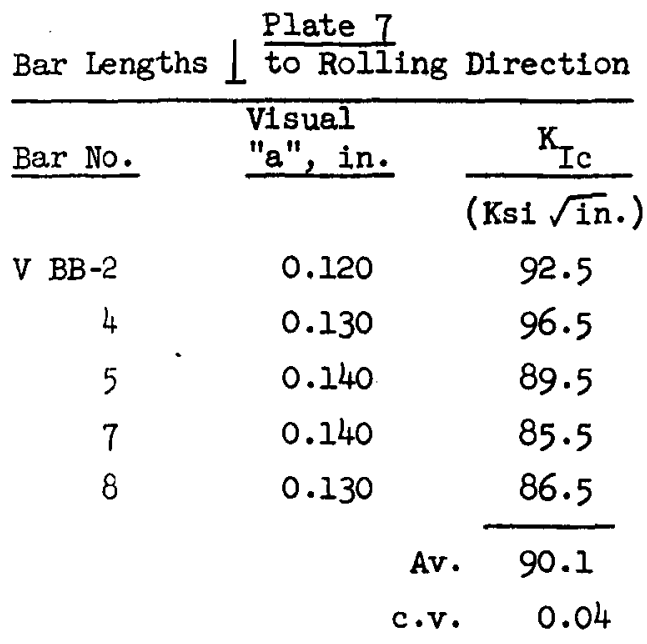

Bar Lengths $\| \frac{\text { Plate II }}{\text { with Rolling Direction }}$

Bar No. $\quad \frac{\text { Visual }}{\text { "a", In. }} \frac{K_{\text {Ic }}}{\left(K_{s i} \sqrt{\operatorname{In} .}\right)}$

$\begin{array}{ll}\mathrm{V} A \mathrm{~B}-1 & 0.12\end{array}$

113.3

$0.13 \quad 96.4$

$0.11 \quad 103.2$

3

0.12

111.3

0.14

101.1

6

0.14

101.1

0.14

120.4

8

0.14

116.2

9

0.14

116.9

10

0.14

98.1

11

0.15

109.9

12

0.15

98.7

13

0.14

102.4

14

0.14

113.4

15

0.14

106.8

16

0.12

115.6

17

0.13

104.5

18

0.15

92.6

Av. 106.8

c.v. $\quad 0.07$ 
Summary of the Test Results

The average $K_{I_{c}}$ values and their coefficients of varlation are shown for the different weld methods, bar orlentations, and notch positions in Table XIII. The coefficients of variation are of about the same magnitude usually reported by other authors and for other test procedures. On this basis the bend test method is not appreciably better or worse than other tests such as the edge notch tear test. The significances of the differences between average $K_{I c}$ values are shown in Table XIV. The levels of significance are assigned on the basis of the probability function of $(t)$ in the usual " $t$ " test. $P(T)$ is the probability that in another set of tests the average values being compared would overlap because of scatter in the results. Qualitative terms used in Table XIV are as follows for designating the differences between averages:

$$
\begin{aligned}
& \text { H.S. = Highly Signiflcant, } \quad P(t)<0.024 \\
& \text { S. = Significant, } \quad P(t) \quad 0.025 \text { to } 0.074 \\
& \text { Pr.S. = Probably significant, } P(t) \quad 0.075 \text { to } 0.14 \\
& \text { Po.S. = Possibly stgnificant, } P(t) \quad 0.15 \text { to } 0.25 \\
& \text { N.S. = Not signiflcant, } \quad P(t)>0.26
\end{aligned}
$$




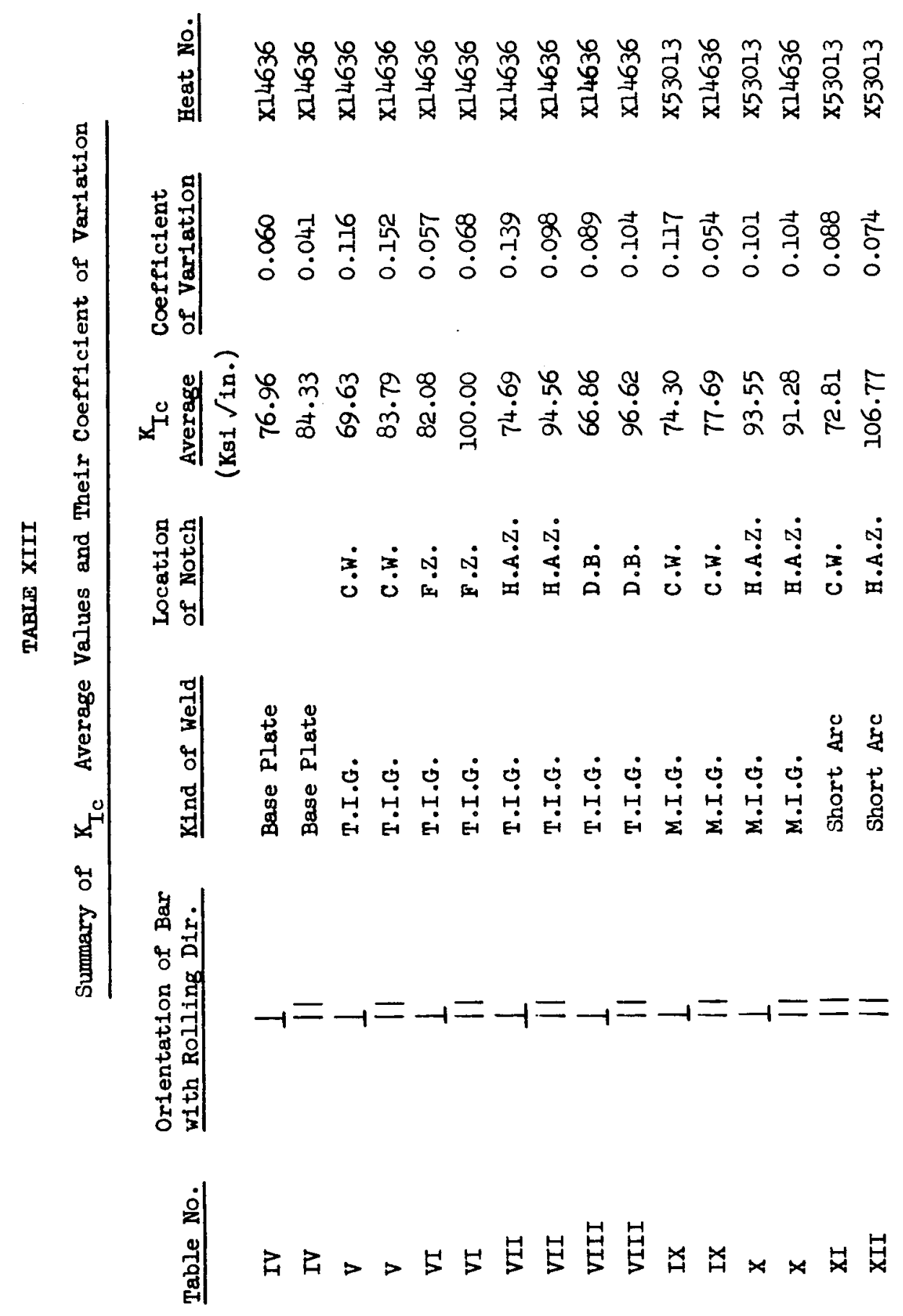


TABLE XIV-Q

$P(t)$ Values for Student's " $t$ " Test of the Significance Between Mean $K_{I_{c}}$ Values

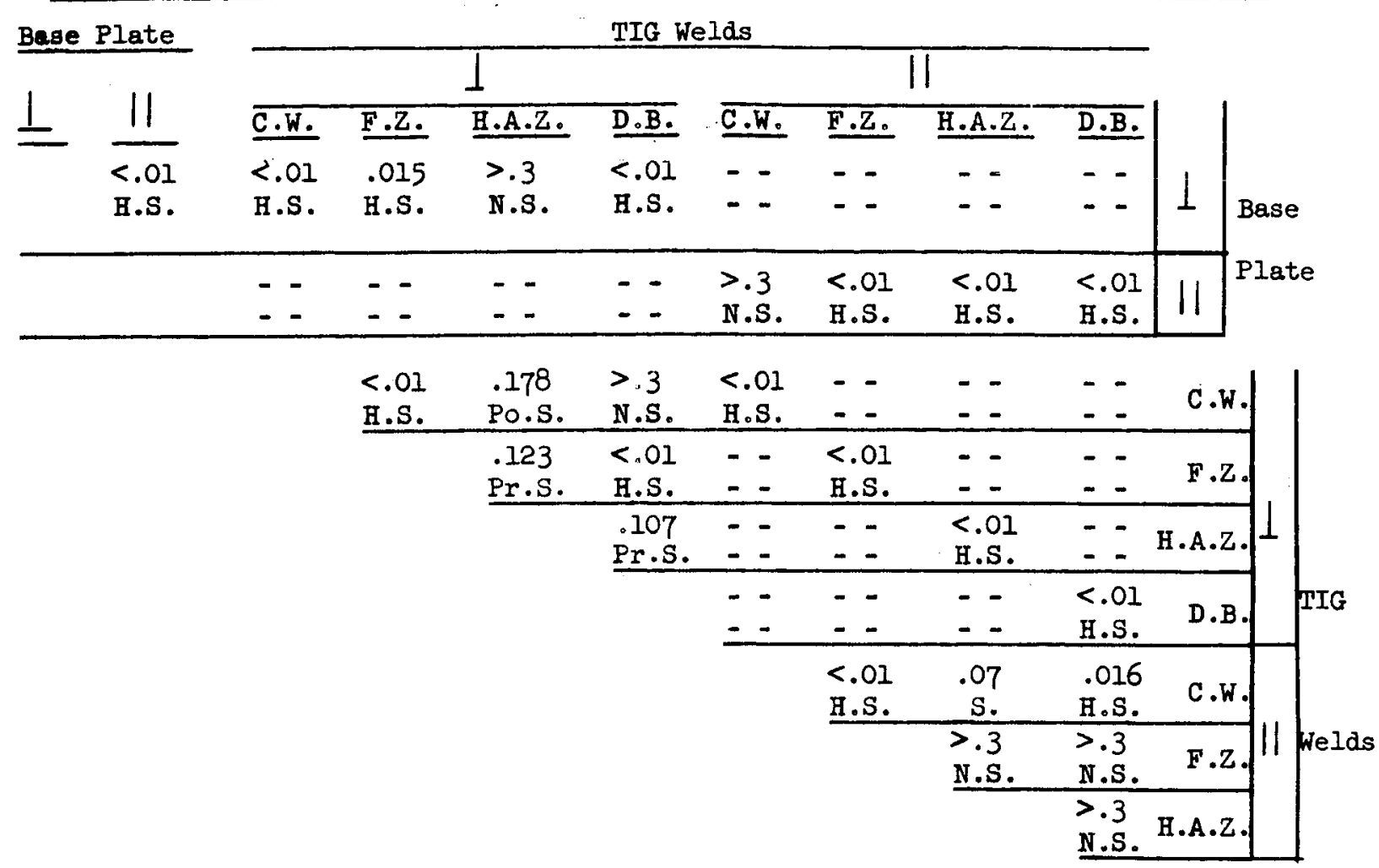

$P(t)$ is the probability of a random variation in average $K_{I c}$ which would equal or exceed the difference shown between two average values of $K_{I c}$.

$$
\begin{aligned}
& \text { H.S. = Highly Significant, } \quad P(t)<0.024 \\
& \text { S. = Significant, } \quad P(t) \quad 0.025 \text { to } 0.074 \\
& \text { Pr.S. = Probably Significant, } P(t) \quad 0.075 \text { to } 0.14 \\
& \text { Po.s. = Possibly Significant, } P(t) \quad 0.15 \text { to } 0.25 \\
& \text { N.S. = Not Significant, } \quad P(t)>0.26
\end{aligned}
$$


TABLE XIV-b

$P(t)$ Values for Student's " $t$ " Test of the Significance Between Mean $K_{I c}$ Values

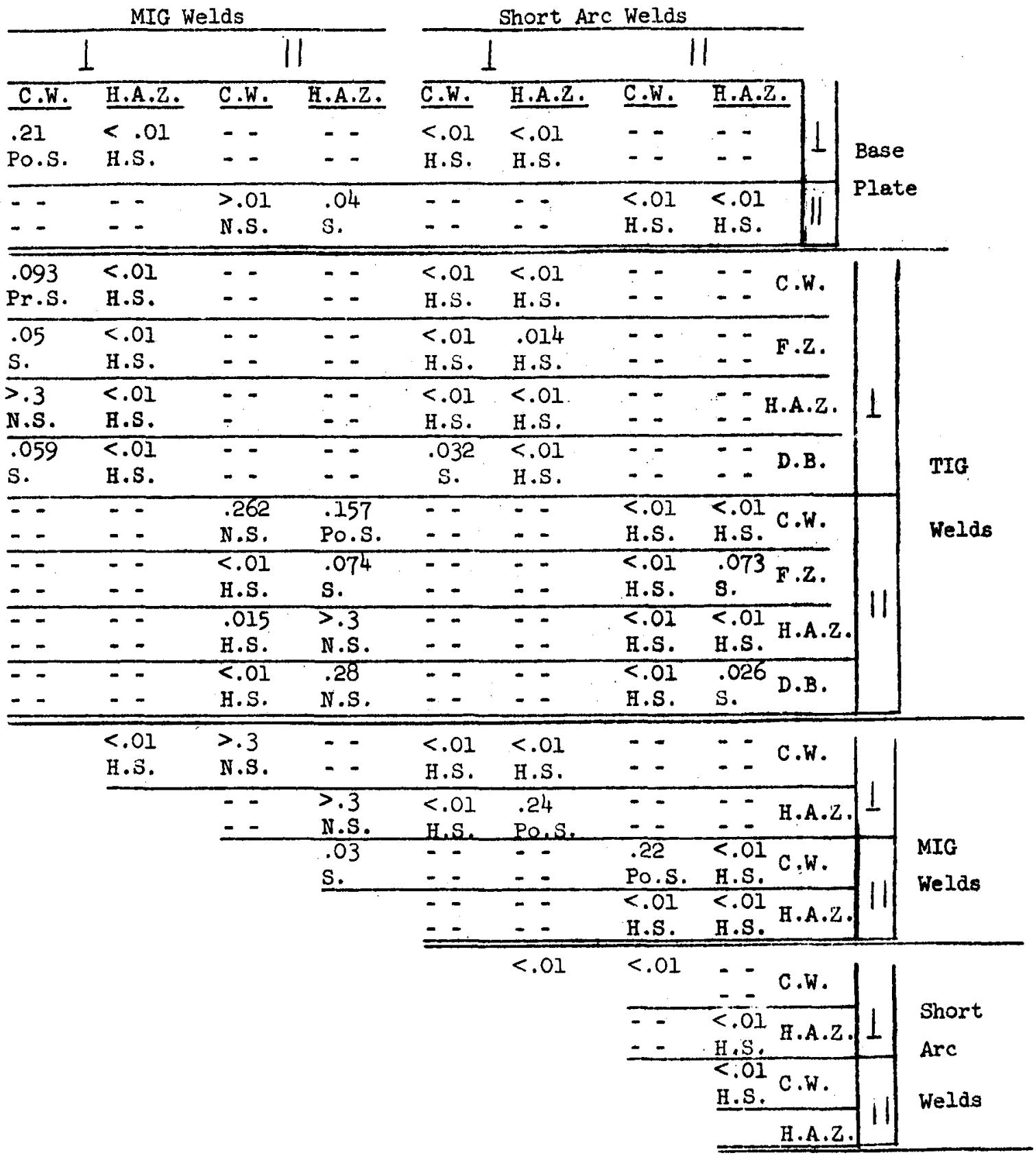




\section{Conclusions}

1. $K_{I c}$ values from the bend tests agreed well with those from edge notched tear tests.

2. A new $K_{I c}$ closed formula for bend tests was obtained which is independent of Young's modulus of elasticlty.

3. There were highly significant effects of rolling direction on $\mathrm{K}_{\mathrm{Ic}}$ for both heats of the 250 grade steel.

4. For TIG welds in bars cut parallel with the rolling direction the average $K_{\text {Ic }}$ values were higher by highly significant amounts than for bars cut perpendicular to the rolling direction. This was true for all four notch positions in the weld. The margins of superlority were magnifled over that in the base plate. We have no explanation.

5. For MIG welds no comparison was avaflable between directions perpendicular and parallel with the rolling direction.

6. For short arc welds the greatest average $K_{I c}$ was found in the heat affected zone. For the $250 \mathrm{Ksl}$ yleld strength steel the directionality effect in the base plate was reflected in the welds.

7. Where a comparison was avallable the TIG welds were more consistent and generally better than for the other types of welds investigated.

8. Where marked superiority of $K_{I c}$ for shallow (vs. deeper) notches in base plate was found, this could be explained on the basis of finer grain size and fewer carbide preclpitates. 
9. Where wide differences in $K_{I c}$ were found between different bars but in the center of the weld at equal depths, the difference correlated with microstructure. Coarse grained weld deposits with dendrites aligned. mainly along the fracture path showed less toughness than fine dendrites randomly oriented.

Conclusions 8 and 9 are tentative and will be given additional study. 


\section{Acknowledgements}

The authors are greatly indebted to the following:

Mr. R. G. Hayes and Mr. A. S. Jennings of the U. S. Naval Weapons

Laboratory and Mr. W. E. Anderson of NRL for mechanlcal testing.

Mr. F. Stonesifer and Mr. Karl McKinney of NRL for calculations.

Mr. W. Cohen and Mr. N. Mayer of NASA Headquarters for the financial support of this research and testing program. 
1. Romine, R.E., "Plane Strain Fracture Toughness Measurements of Solid Booster Case Materials," U. S. Naval Weapons Laboratory Report No. 1884, 13 September 1963.

2. Nast, P., Private communication, not publisheà.

3. Irwin, G.R., "The Crack Extension Force for a Crack at a Free Surface Boundary," NRL Report 5120, Apr11 15, 1959.

4. Gross, B., Private communfcation.

5. Romine, H.E., "Plane Strain Fracture Toughness by the Slow Bend. Test and Through-Th1ckness Tensile Properties of Unwelded $18 \mathrm{Ni}$ (250) Maraging Steel Plate 3/4-1nch Thlck belng Studied for use in Large Solid-Propellant Booster Rockets," NWL Report (to be published).

6. U. S. Steel Corp. letter of $11 \mathrm{Feb} 1963$ to Dr. J. M. Krafft.

7. Winne, D.H. and Wundt, B.M., "Application of the Griffith-Irwin Theory of Crack Propagation to the Bursting Behavior of Disks Including Analytical and Experimental Studies," ASME Paper No. 52A-249, presented December 1957. 


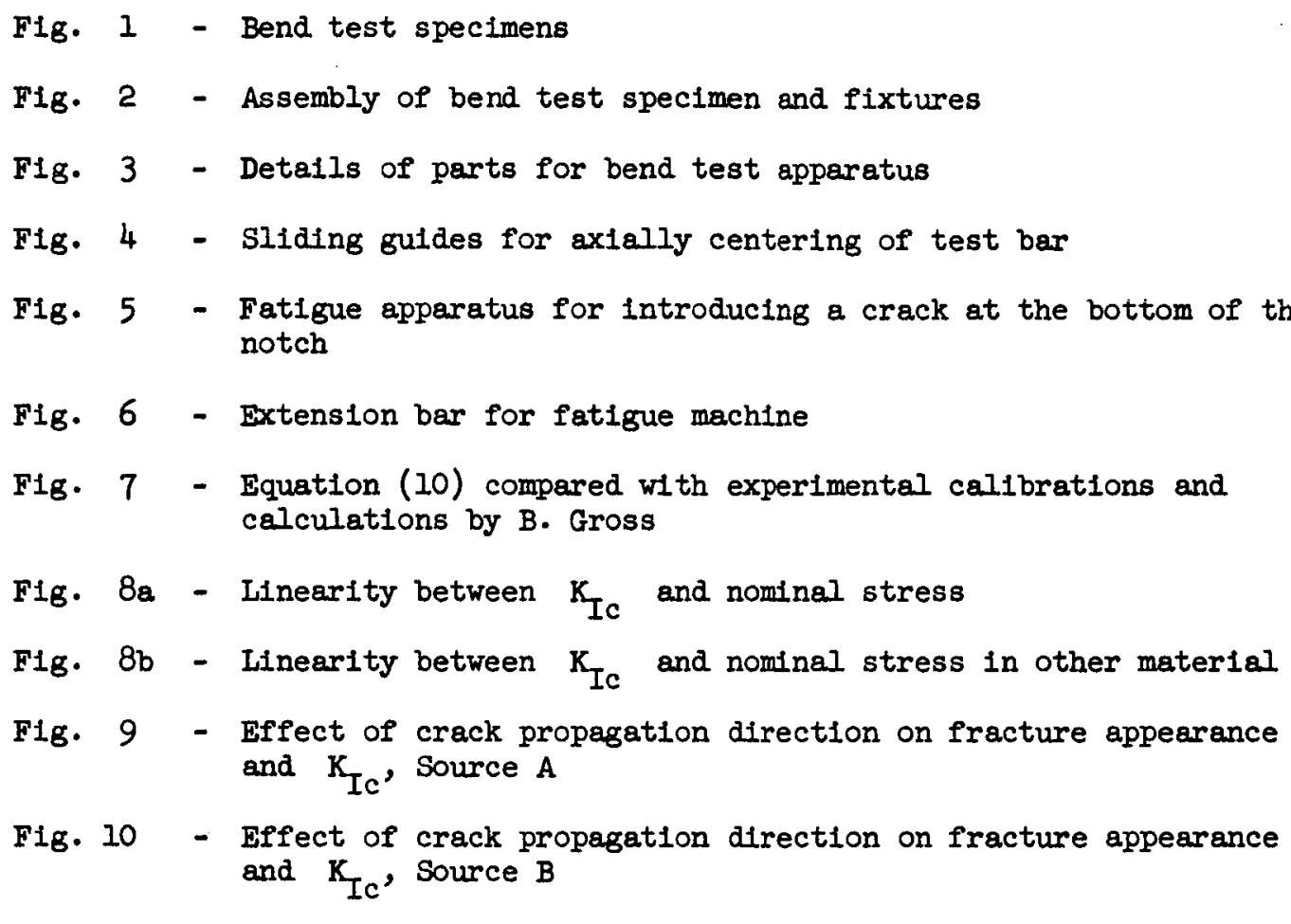

F1g. 11 - Appearance of crack propagation through the thickness and across the rolling direction NRL Plate 2

F1g. 12 - Appearance of crack propegation from an edge notch propagating across the rolling direction in NRL Plate 2

Fig. 13a - Etched bars showing TIG lay up and position of notches in NRL Plate 2

Fig. 13b - Etched bars showing MIG lay up and position of notches in NRL Plate 2

Fig. 13c - Etched bars showling short arc welds lay-up and position of notches in NRL Plate 2.

Fig. 14 - Cross section of weld area showing different locations of starting notch tipped with fatigue crack

Fig. Al - Enlarged view of a fracture origin in a 156-1nch diameter test chamber made of $\mathrm{H}-11$ steel. 


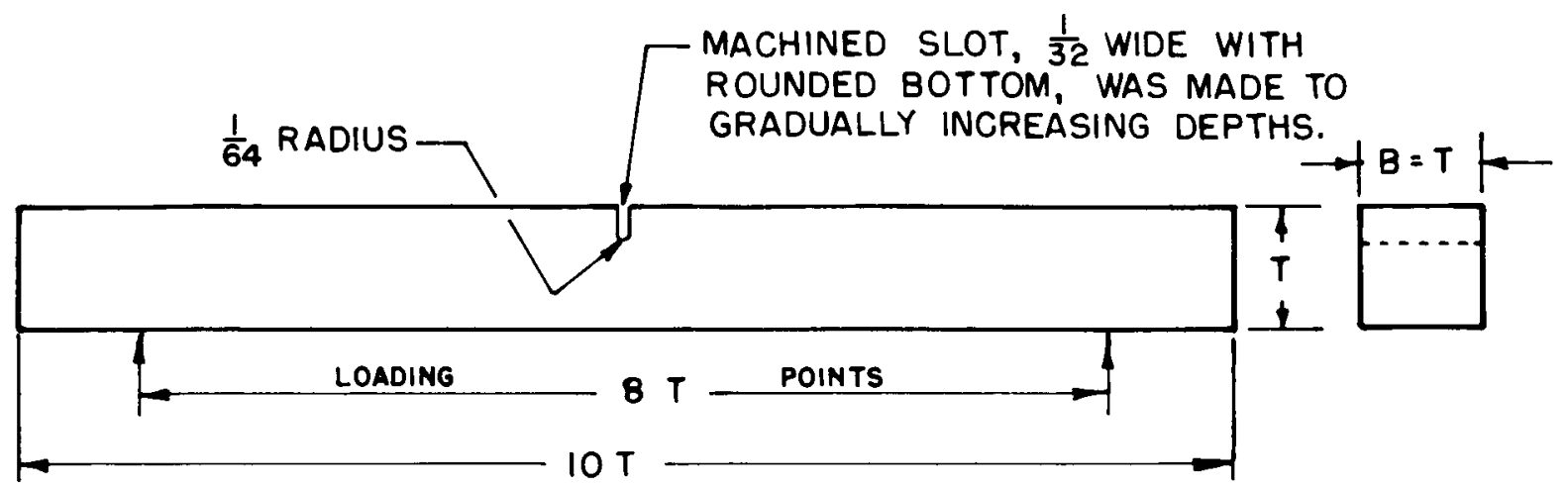

A. CALIBRATION BAR FOR DETERMINING SPRING CONSTANTS

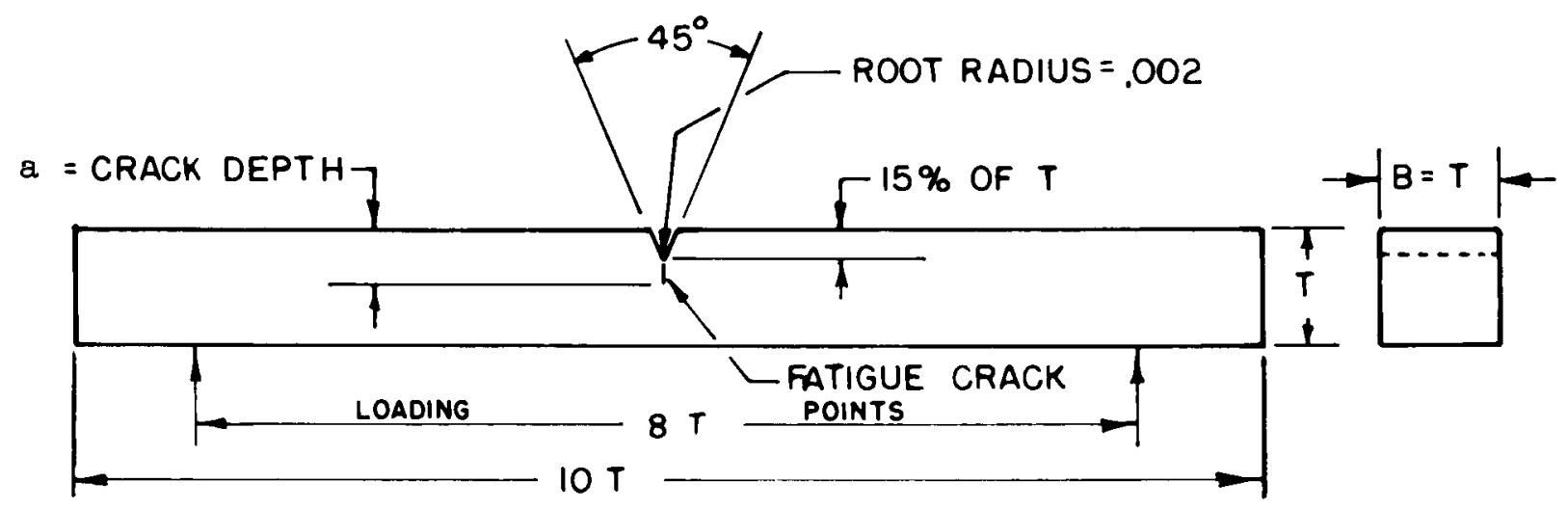

B. TEST BAR FOR $G_{I_{C}}$ VALUES

Figure 1.- Sketches of notched bar specimens. 


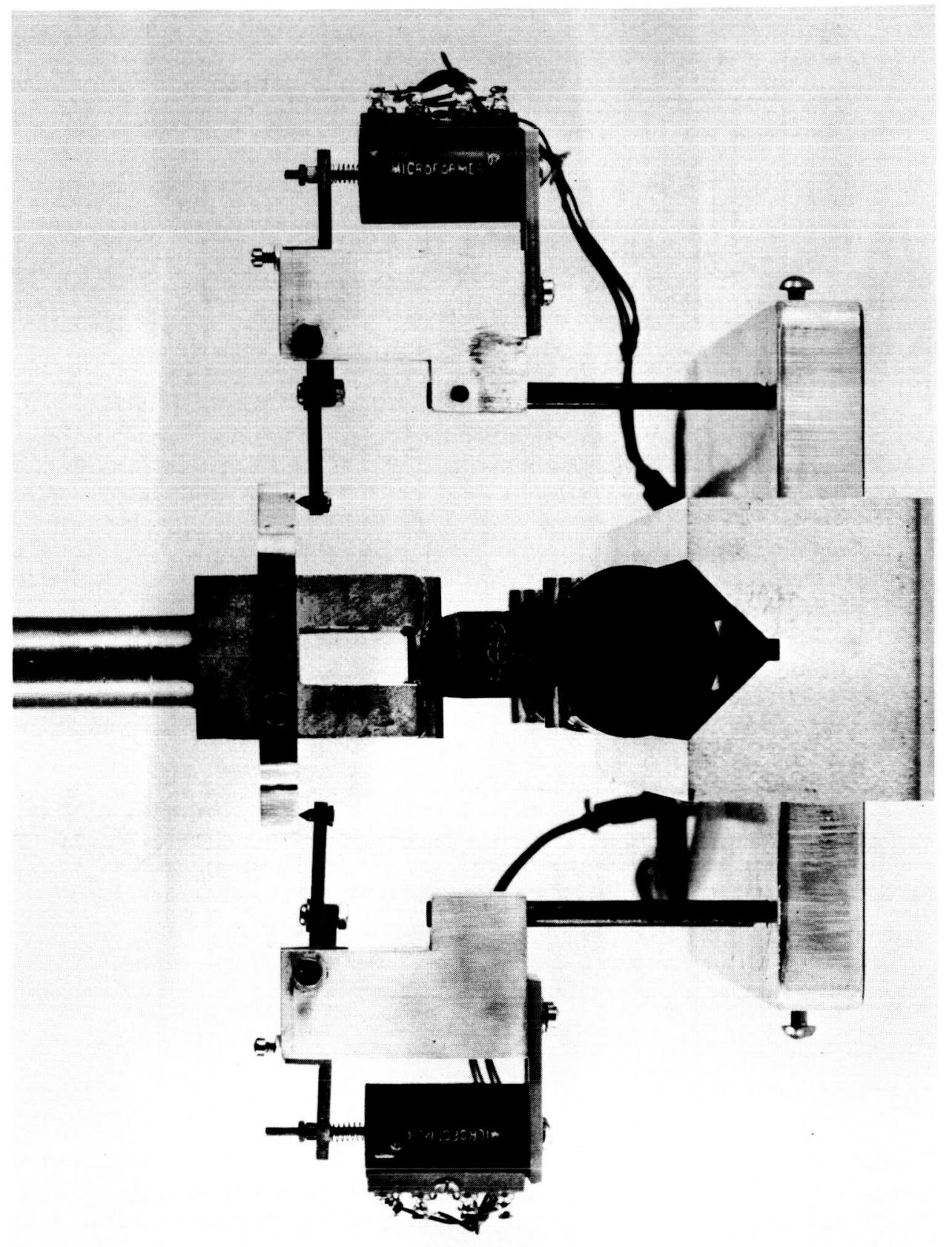

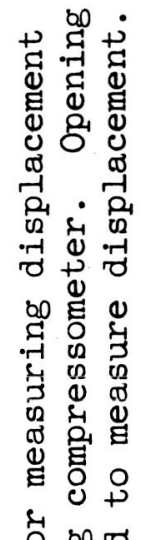
क्ष 000 द 505 त ก

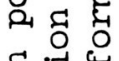
द्व थ टु हु है का क्ष 덤 कृ ट : \& $C$ 4 b0 0. С્ त्न

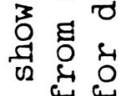
यक से गै त्व ๙ สิ ฮี

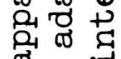
$\begin{array}{lll}0 & 0 \\ 0 & 0 & 0 \\ 0 & 0 & \pi \\ 0 & 3 & 3\end{array}$ व 'ृ क्ष ब 4 20 สี .7 उद्व $\rightarrow$ 年 돕.

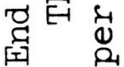
। ते ن त 㿭 . 

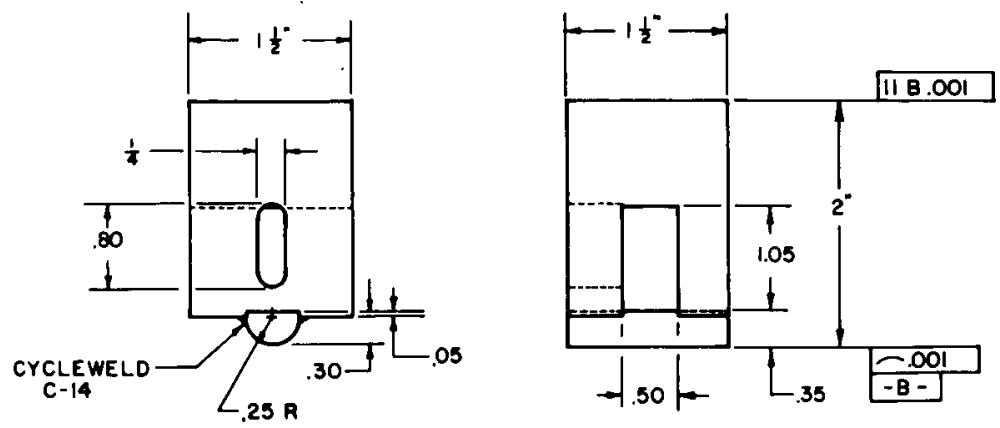

(A)
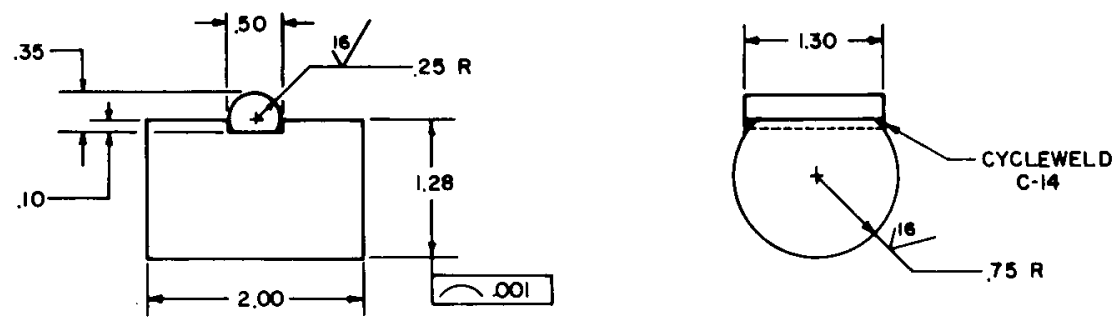

(A2) (2 REOD)
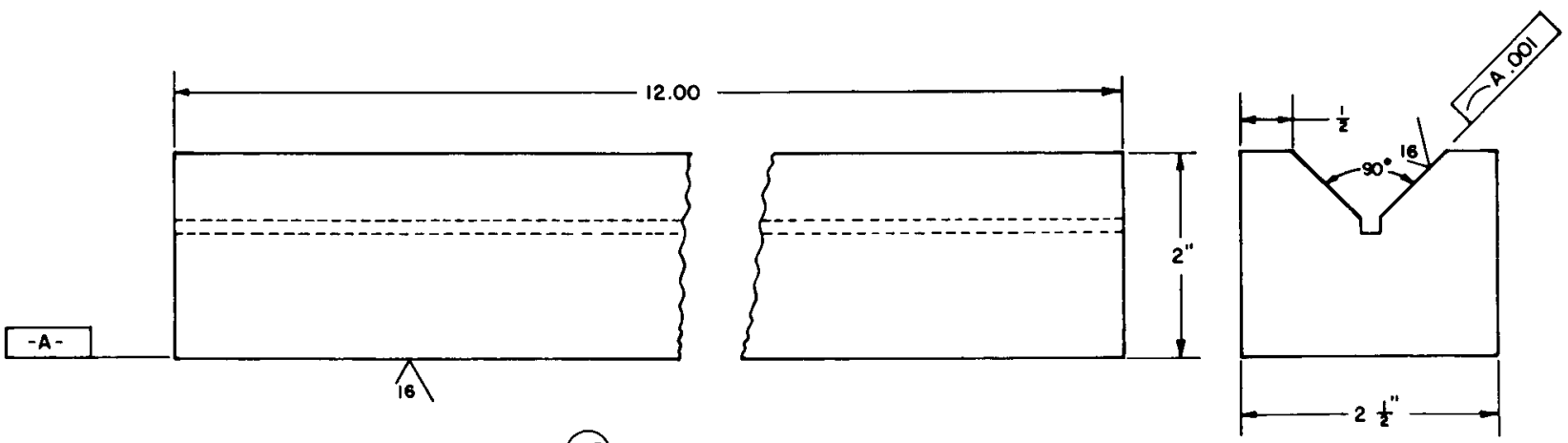

(23)

Figure 3.- Details of parts for bend test apparatus. The loading bars were 4340 steel hardened to 48 Rockwell $\mathrm{C}$. The other parts were machined from quenched and tempered alloy steel with a hardness of about 26 Rockwell $\mathrm{C}$ (STS armor steel). Loading bars were cemented in place with Cycleweld C-14 adhesive (Chrysler Corp.) or equivalent. 


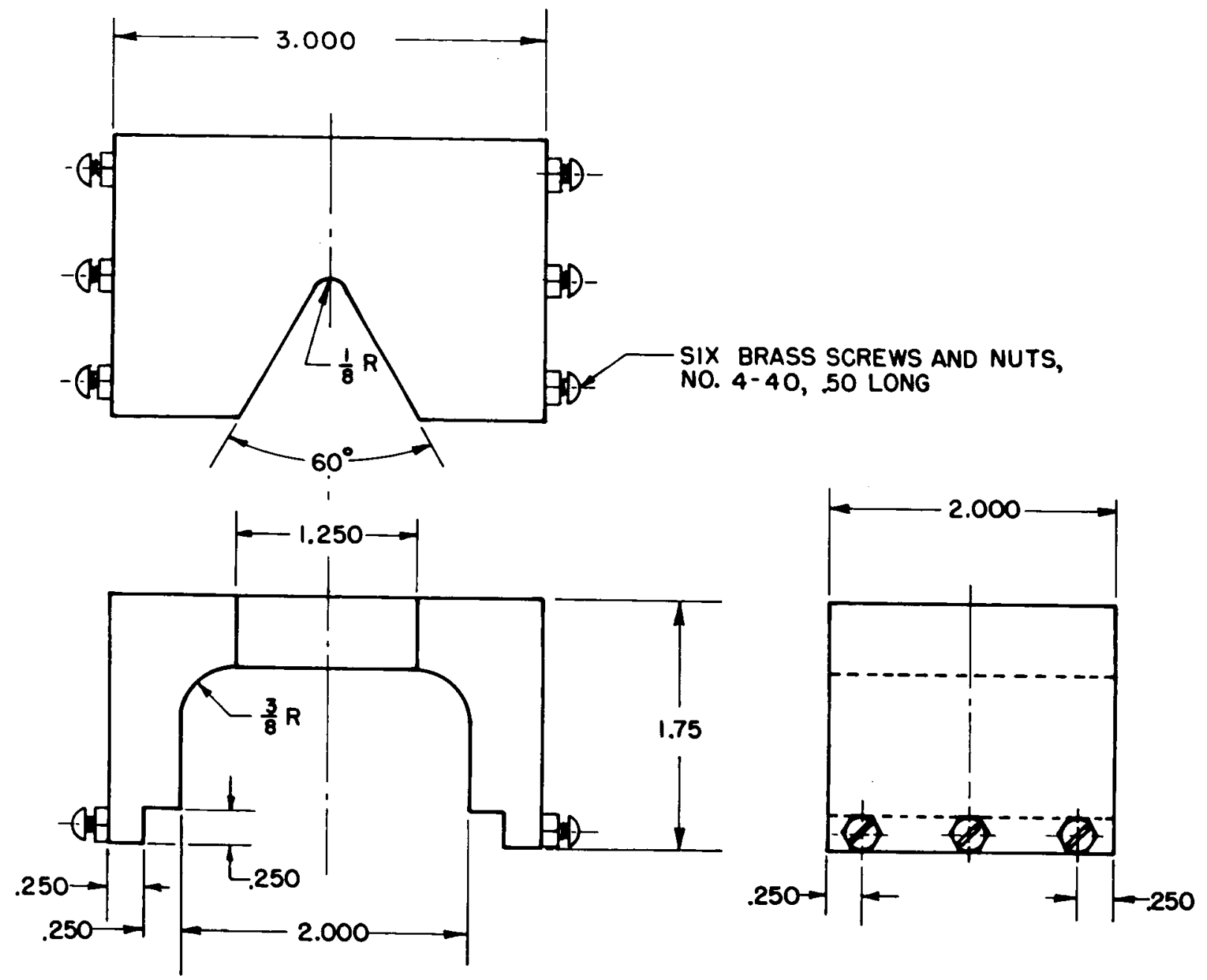

Figure 4.- Sliding guides for axial centering of test bar. Material: 2024-T4 aluminum alloy. Make two. 


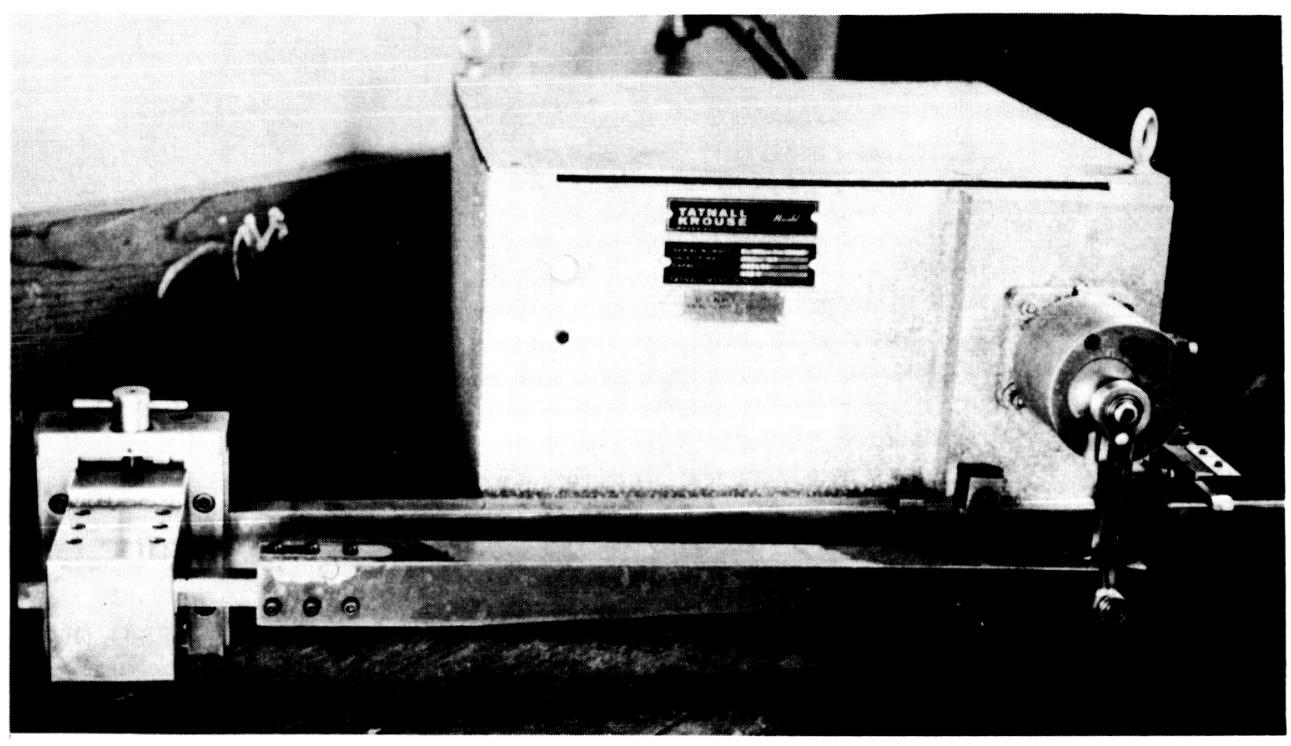

(A) Plate fatigue machine adapted to introduce fatigue crack at root of machined notch in bend test bars.

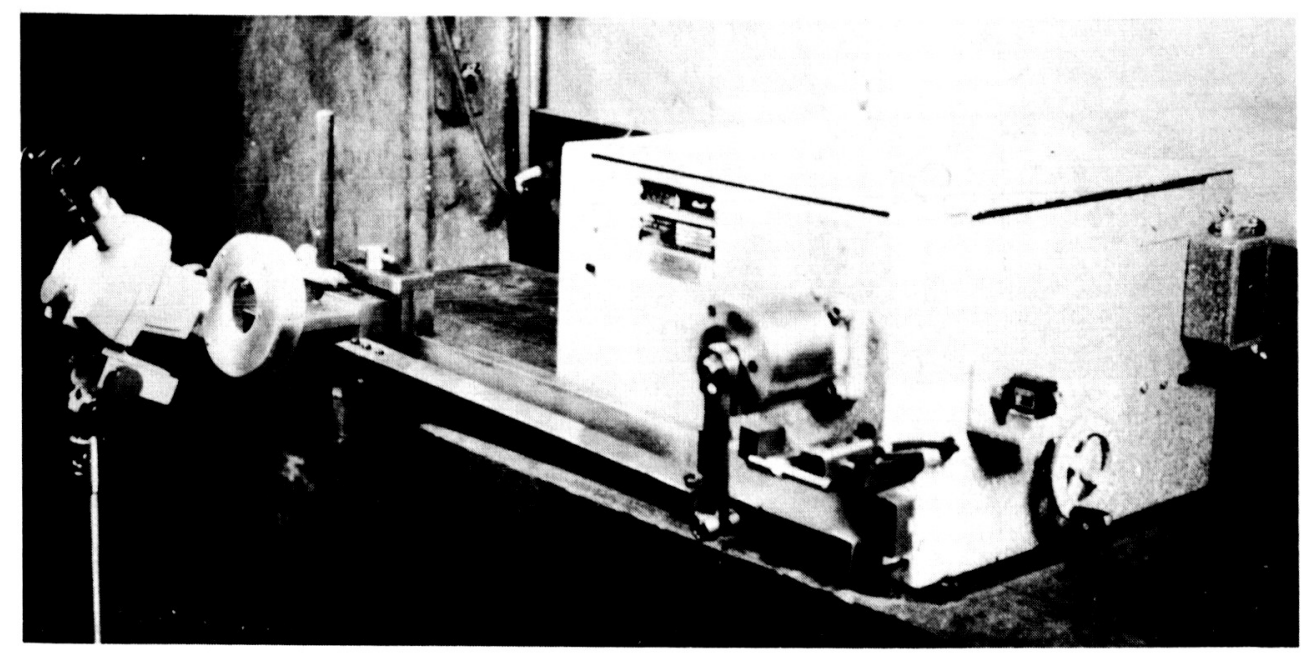

(B) Machine is stopped at intervals to inspect progress of fatigue crack. A zocm microscope and ring fluorescent light are shown in position to inspect front edge of crack. Microscope is racked in and a small firstsurface mirror is held in position to inspect crack at back of notch.

Figure 5. - Fatigue machine for bend test bars. 


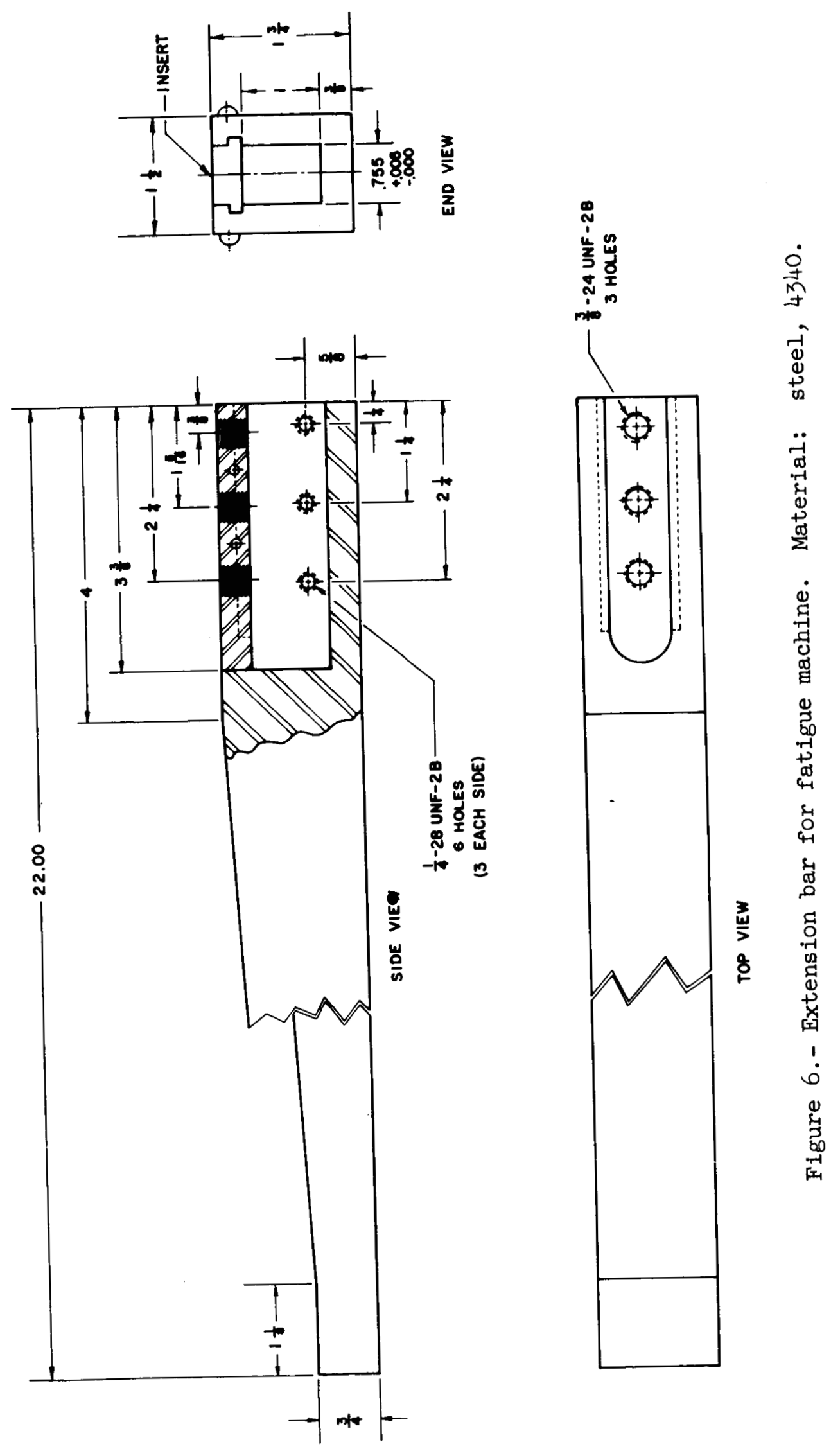




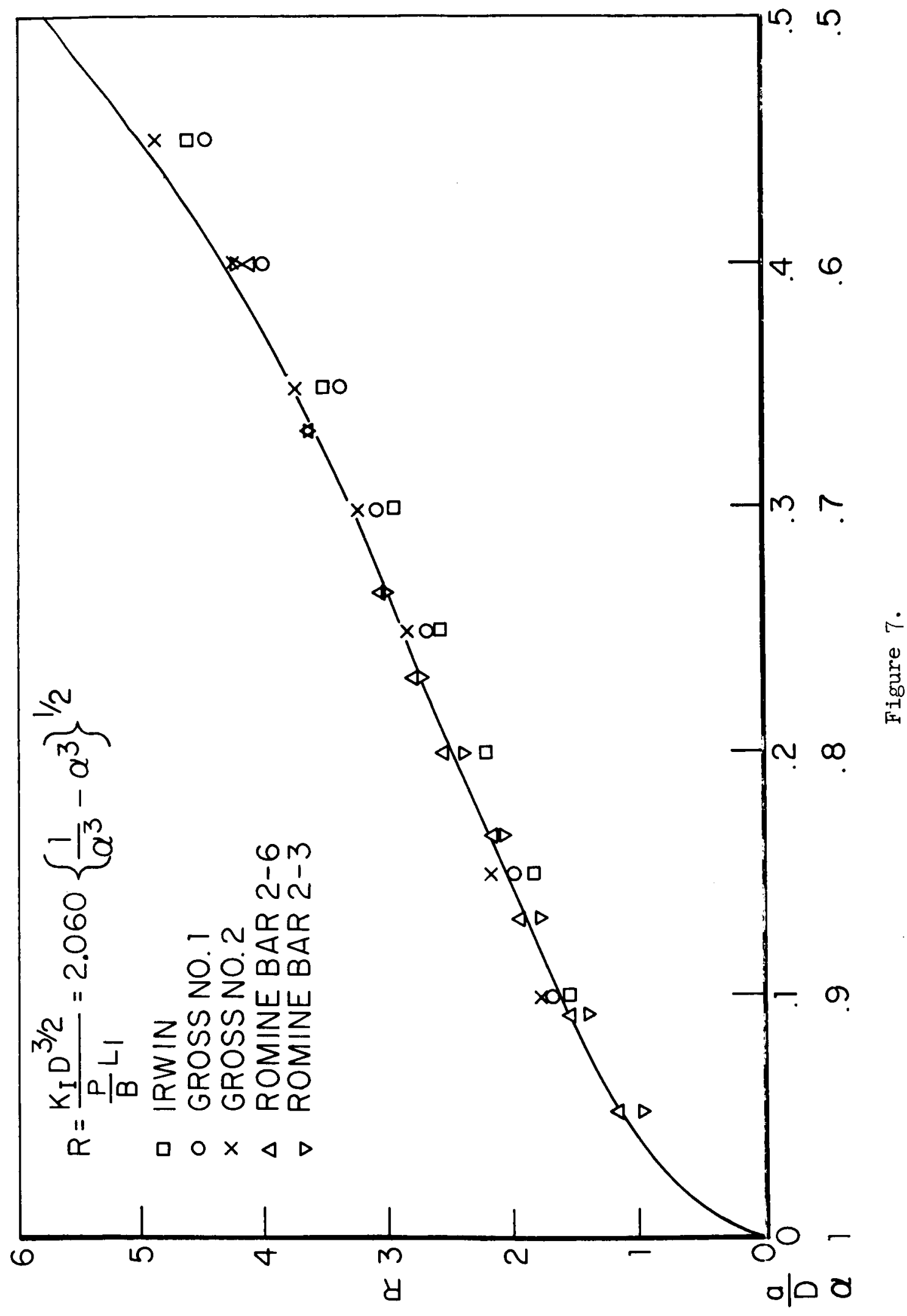




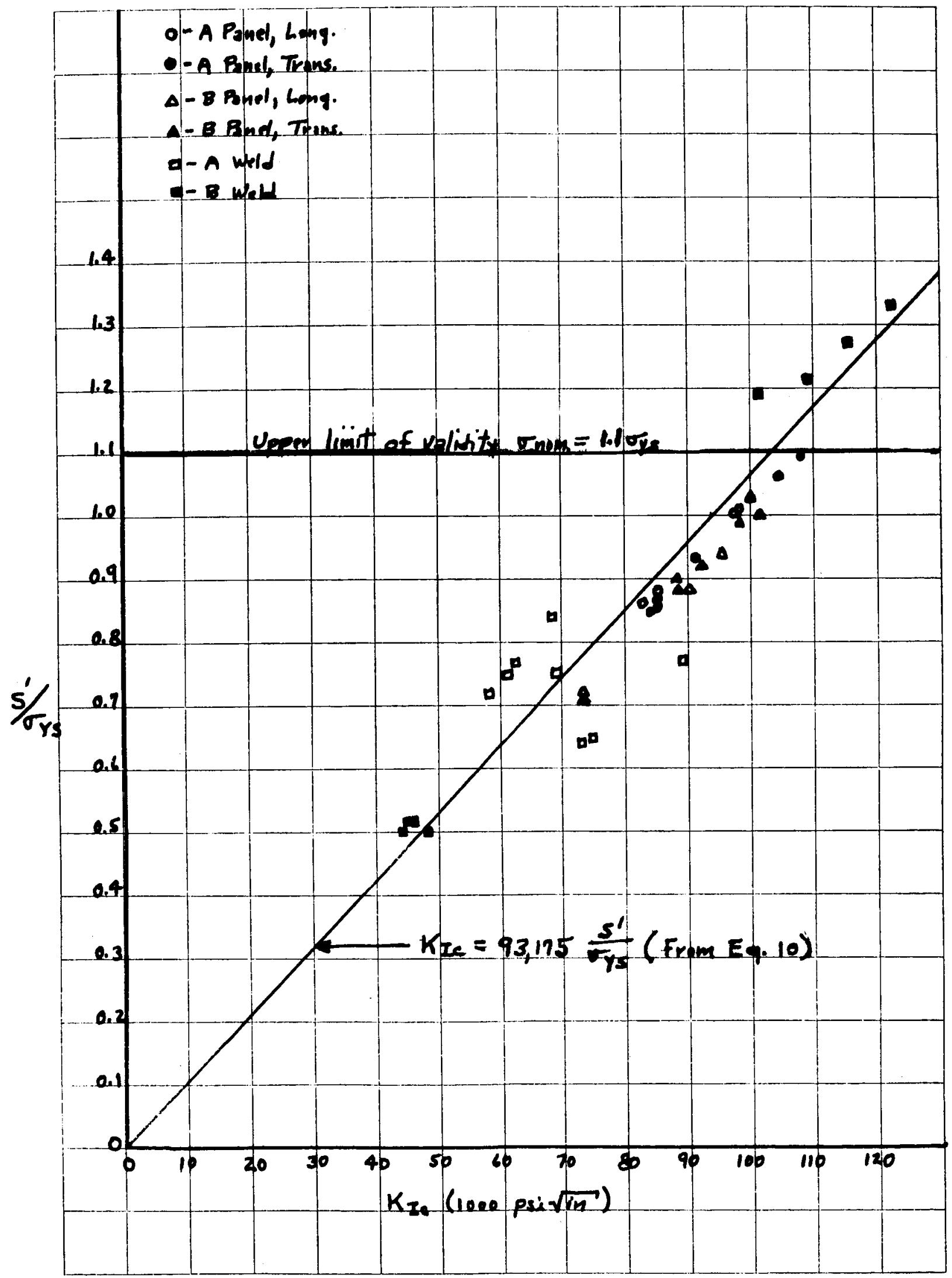

Figure 8a. 


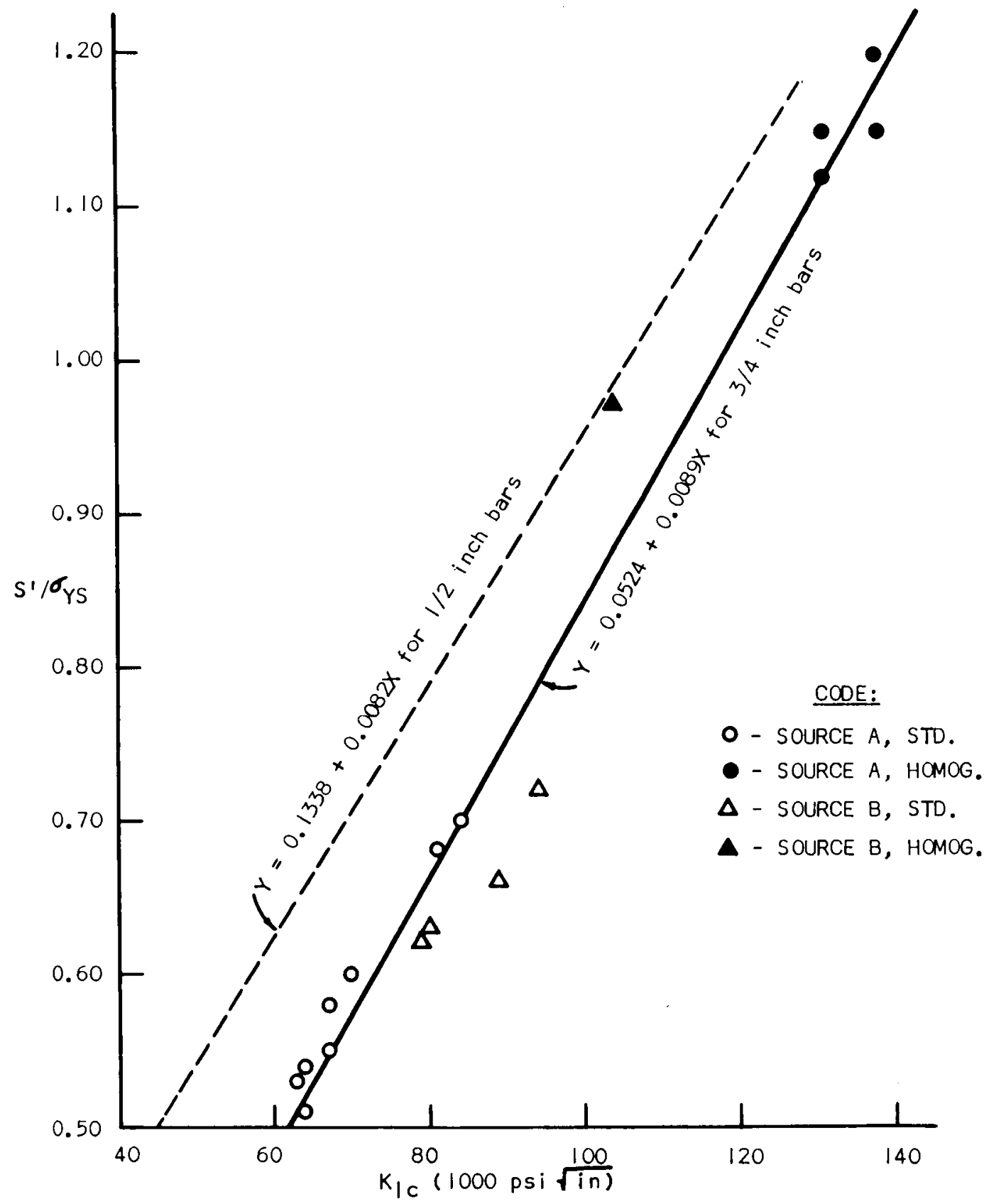

Figure 8b.- Correlation between ratio of maximum fiber stress to yield strength $\mathrm{S}^{\prime} / \sigma_{Y S}$ and fracture toughness $\mathrm{K}_{\mathrm{Ic}}$. Data points and solid line are for $3 / 4$ inch bars in this report. The dashed line is a regression line for data on $1 / 2$ inch bars from NWL report No. 1884 . All $\mathrm{K}_{\mathrm{Ic}}$ results were calculated from $\boldsymbol{y}_{\mathrm{Ic}}$ by the relation: $\mathrm{K}_{\mathrm{Ic}}^{2}=\frac{\boldsymbol{E}_{\mathrm{Ic}}}{\left(1-v^{2}\right)} \cdot S^{\prime}$ was calculated by the formula: $S^{\prime}=\frac{6 L}{4(d-a)^{2}}\left(\frac{P}{B}\right)$. 
Avg. Klc $-66,000$ psi $\sqrt{\text { in }}$

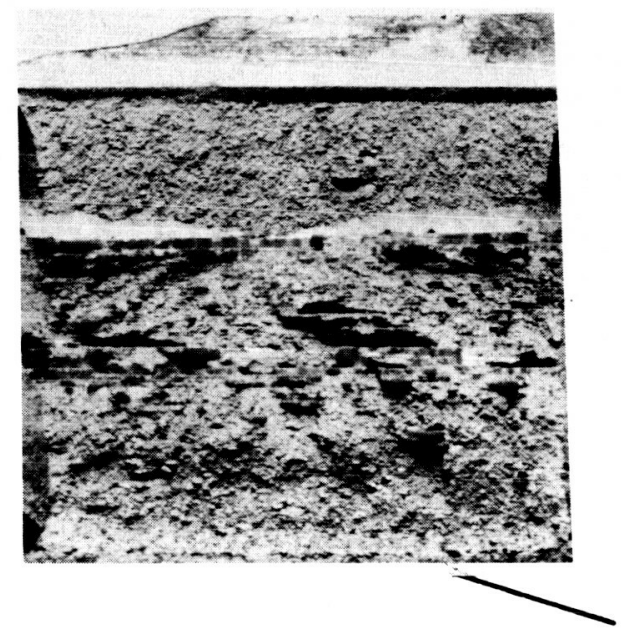

Avg. KIc $-83,000$ psi $\sqrt{i n}$
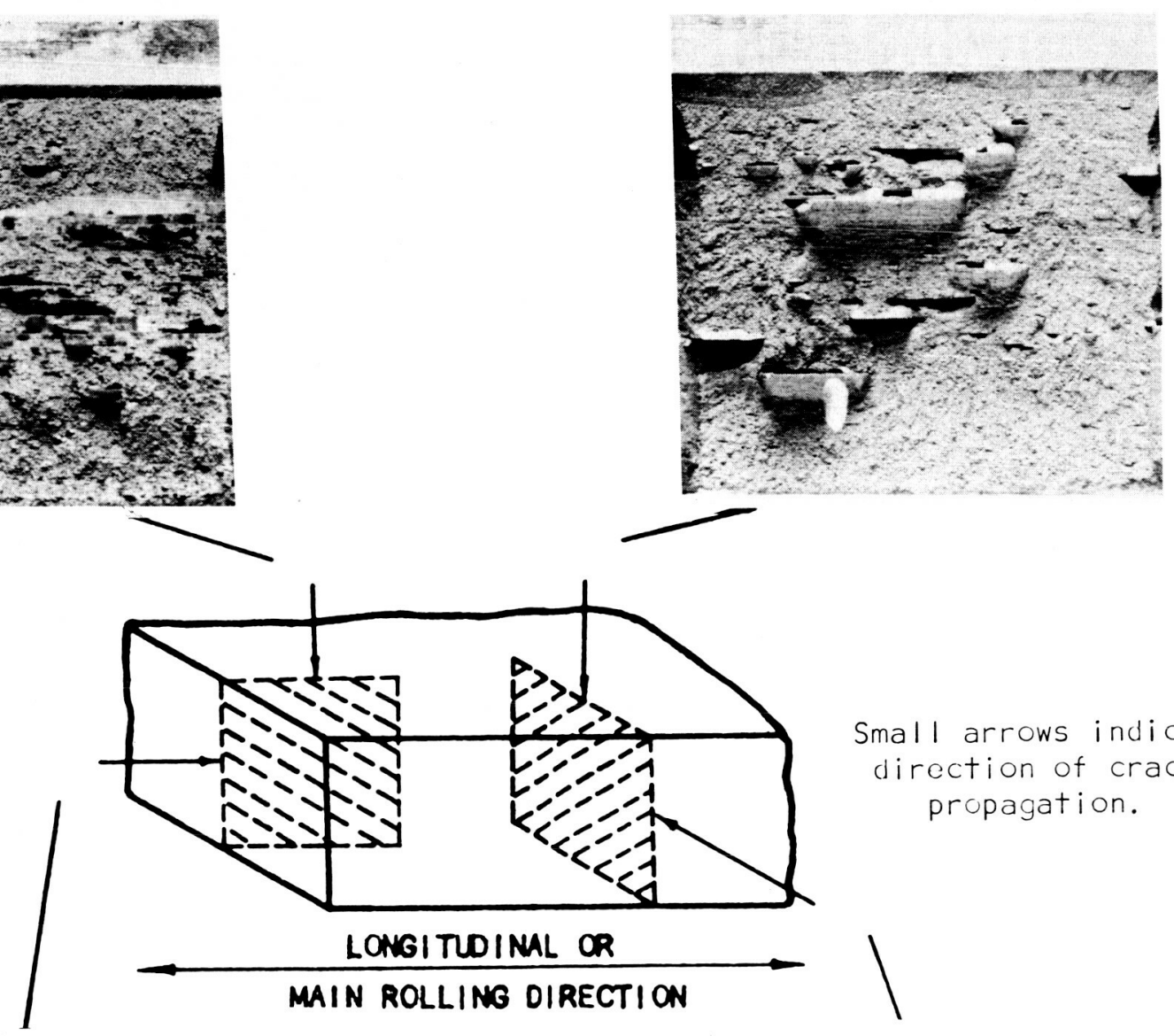

Small arrows indicate direction of crack propagation.

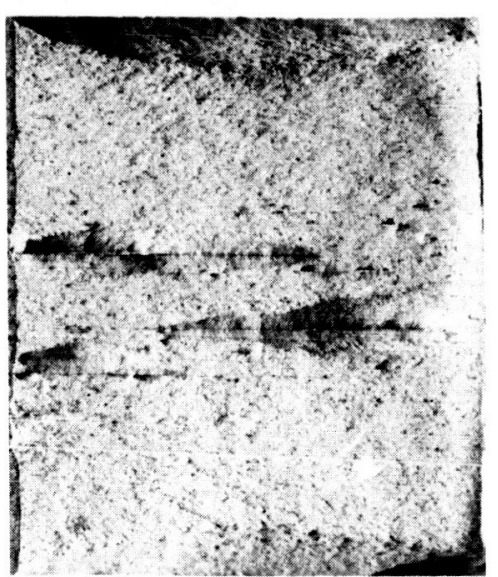

Avg. $K_{\mid c}-64,000$ psi $\sqrt{\text { in }}$

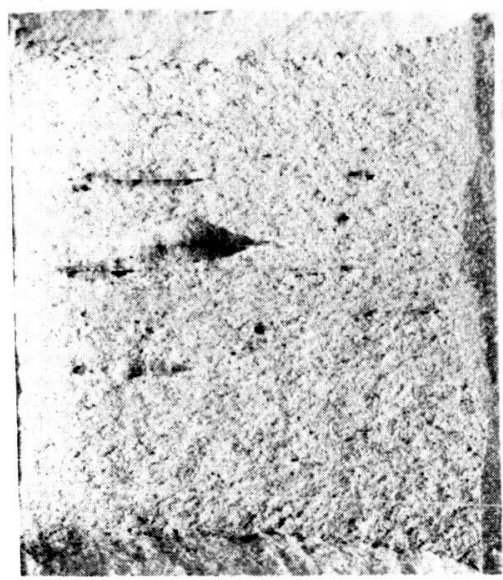

Avg. $K_{1 c}-69,000$ psi $\sqrt{\text { in }}$

Figure 9.- Fracture appearance of slow-bend tests made to determine directional fracture toughness in $18 \mathrm{Ni}$ (250) maraging steel plate $3 / 4$ inch thick from source A. $\times 3$. 


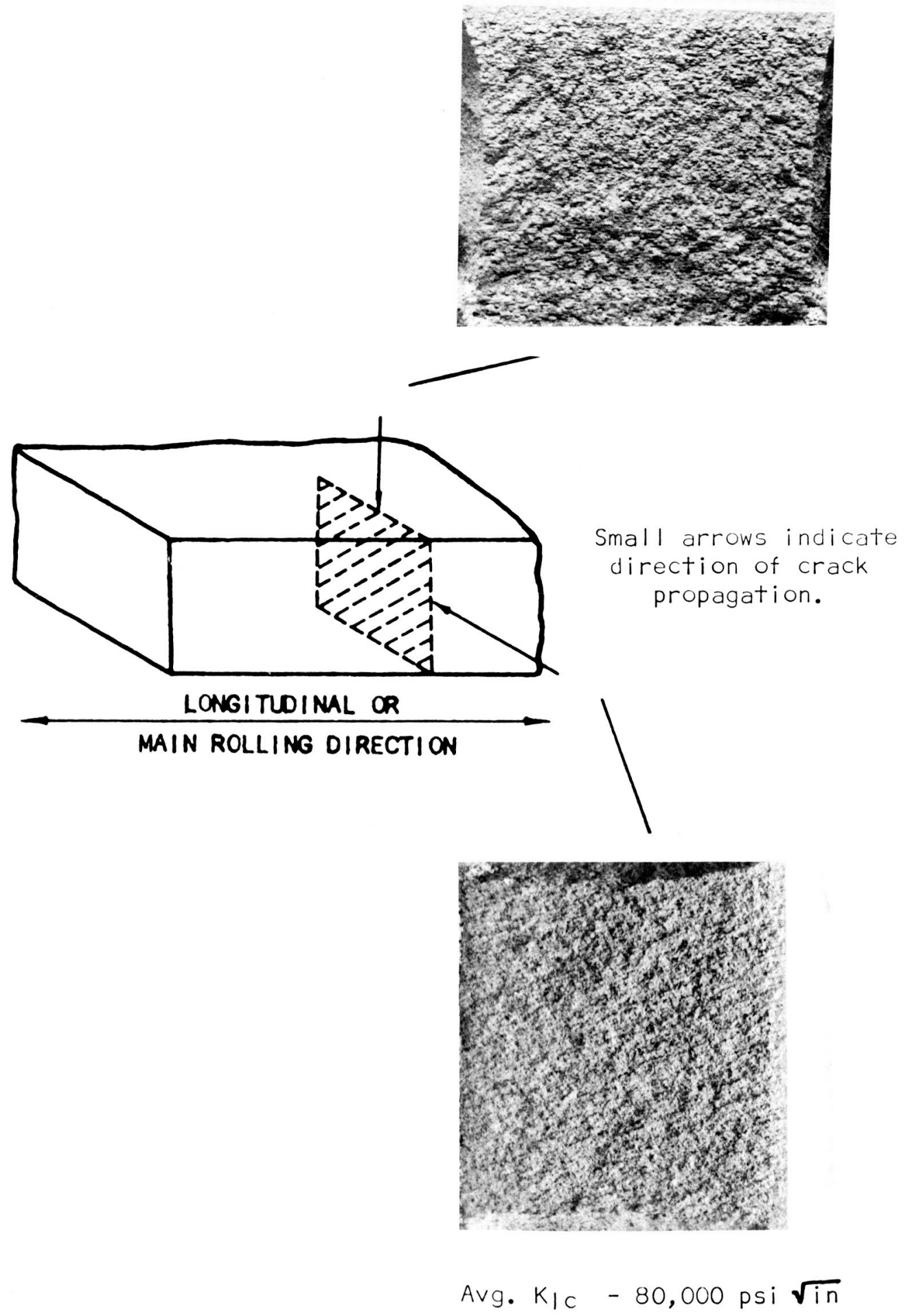

Figure 10.- Fracture appearance of slow-bend tests made to determine directional fracture toughness in $18 \mathrm{Ni}$ (250) maraging steel plate $3 / 4$ inch thick from source $B . \times 3$. 


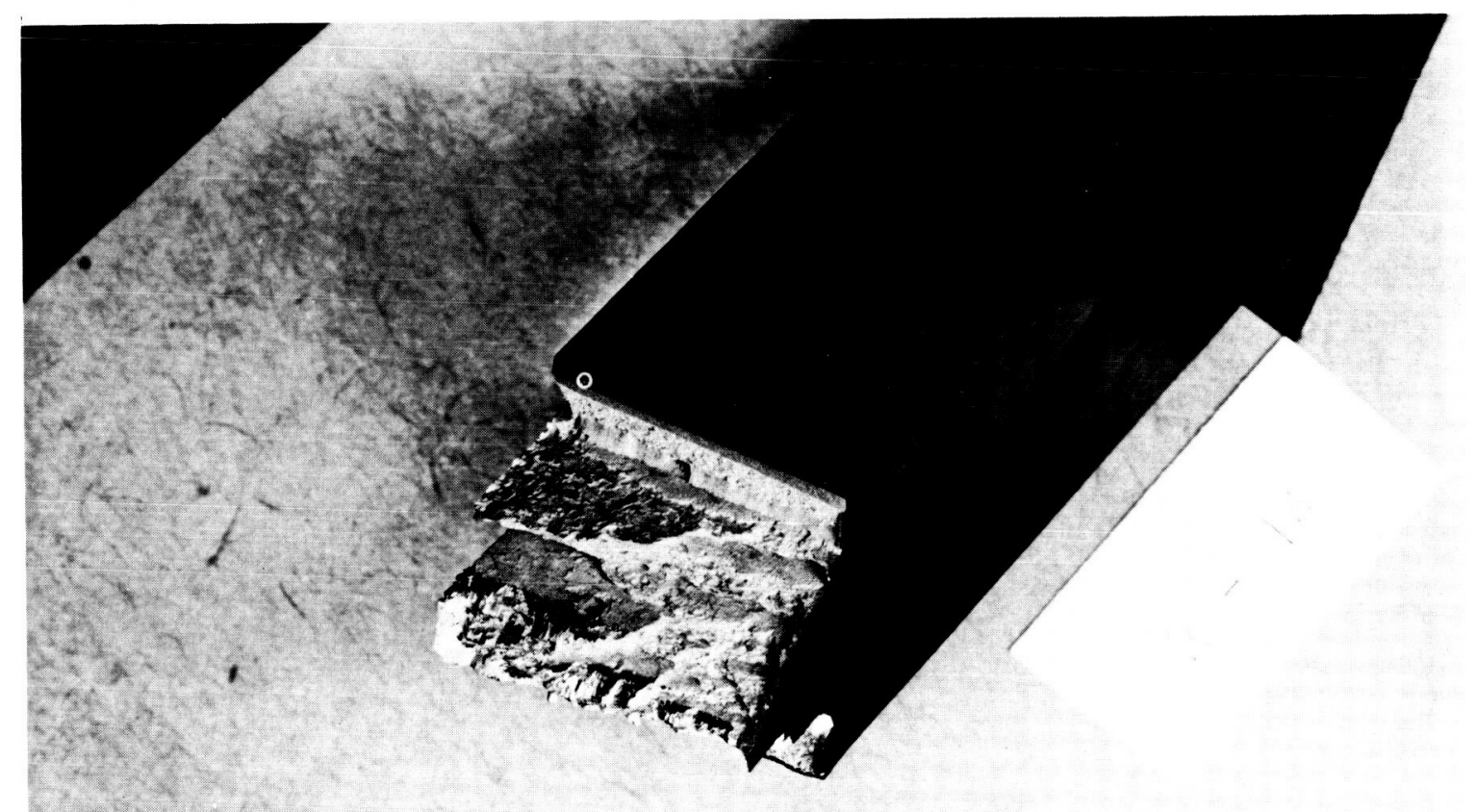

Figure 11. 


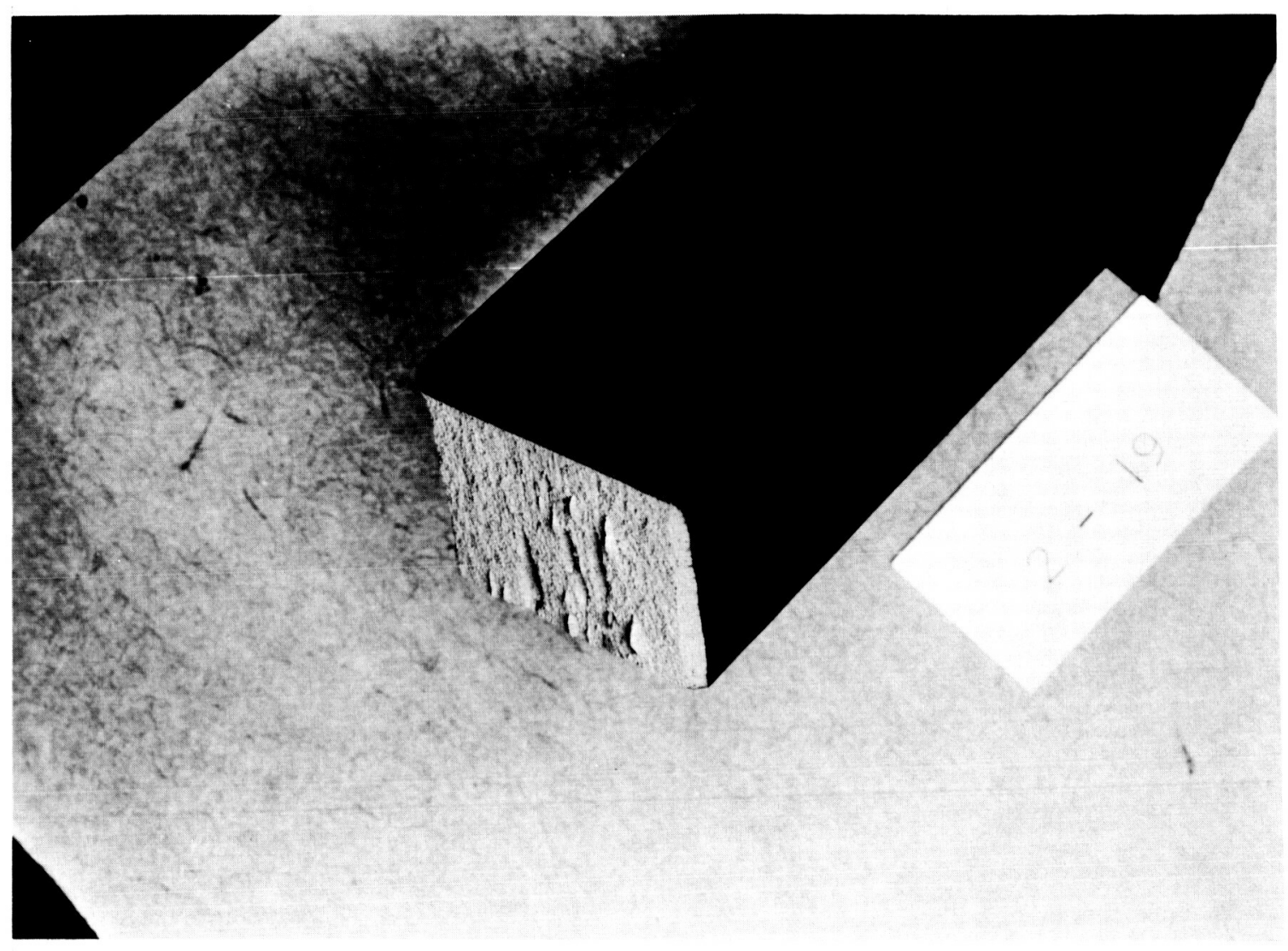

Figure 12. 


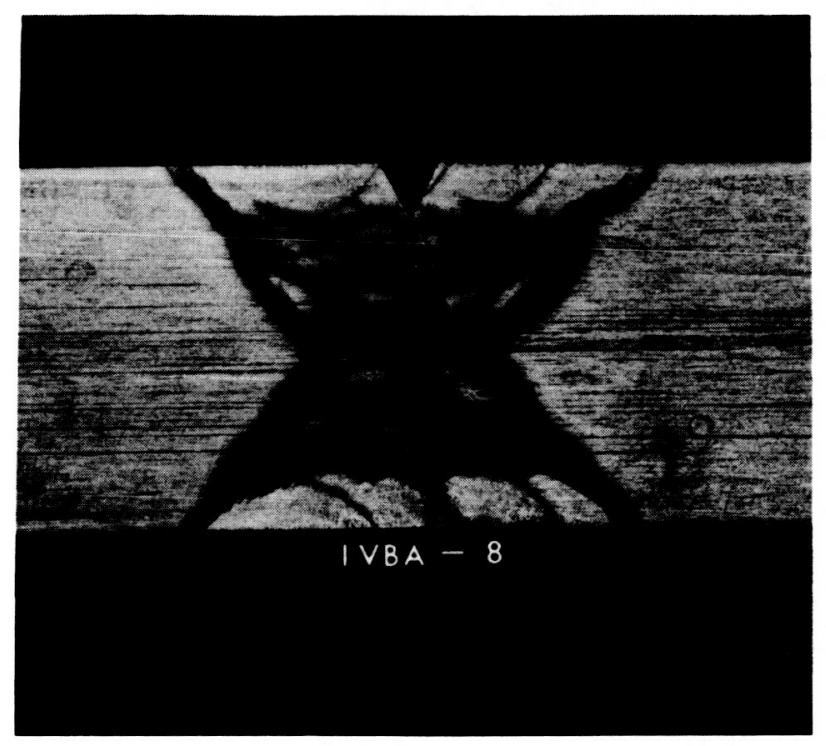

(A) Notch in center of weld

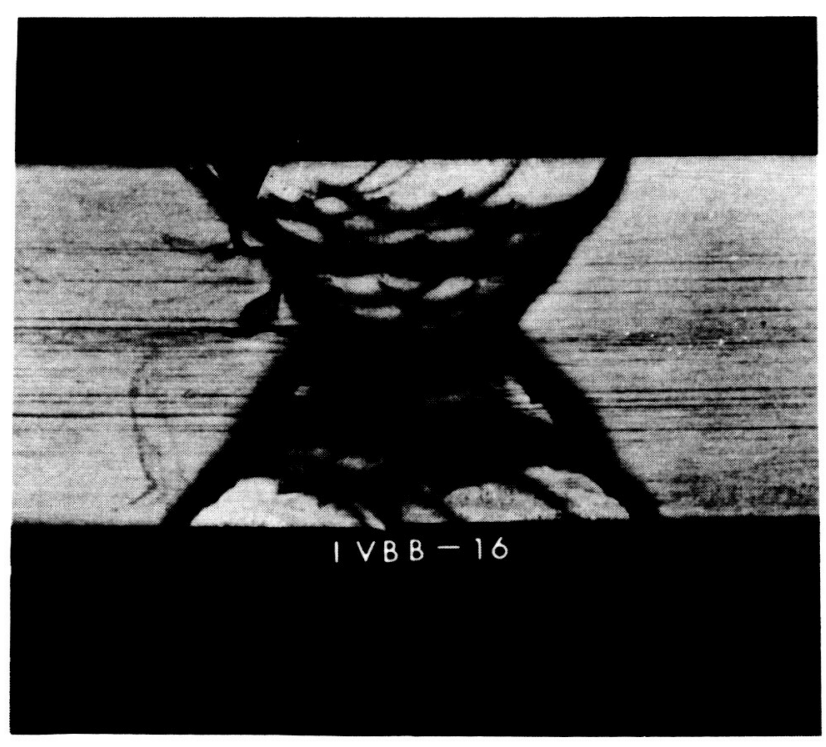

(C) Notch within heat-affected zone

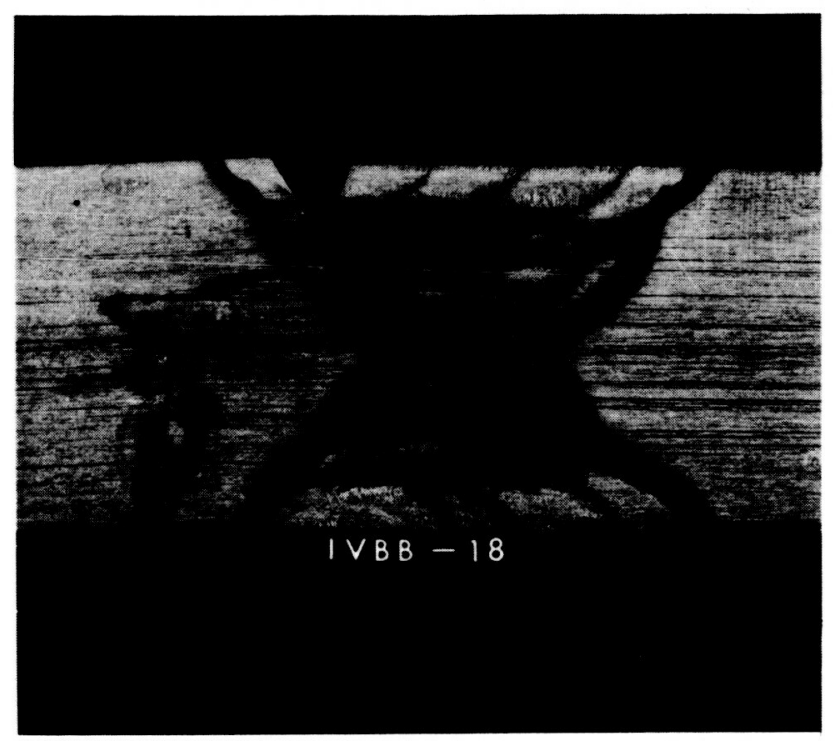

(B) Notch at edge of weld fusion zone fusion zone.

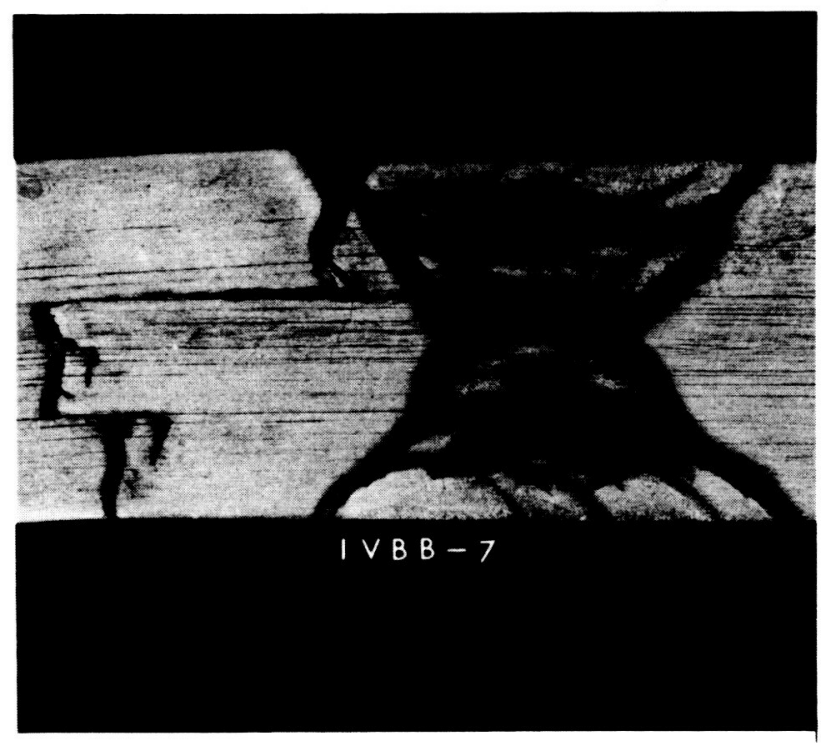

(D) Notch at juncture of heat-affected zone and base metal.

Figure 13a.- Side views of typical bend bars after $\mathrm{K}_{\mathrm{Ic}}$ tests of TIG weld in plate 2 - $18 \mathrm{Ni}$ (250) maraging steel. Plate cross sections transverse to rolling direction showing different locations of starting notch tipped with fatigue crack. Etched, $\times 2$. 


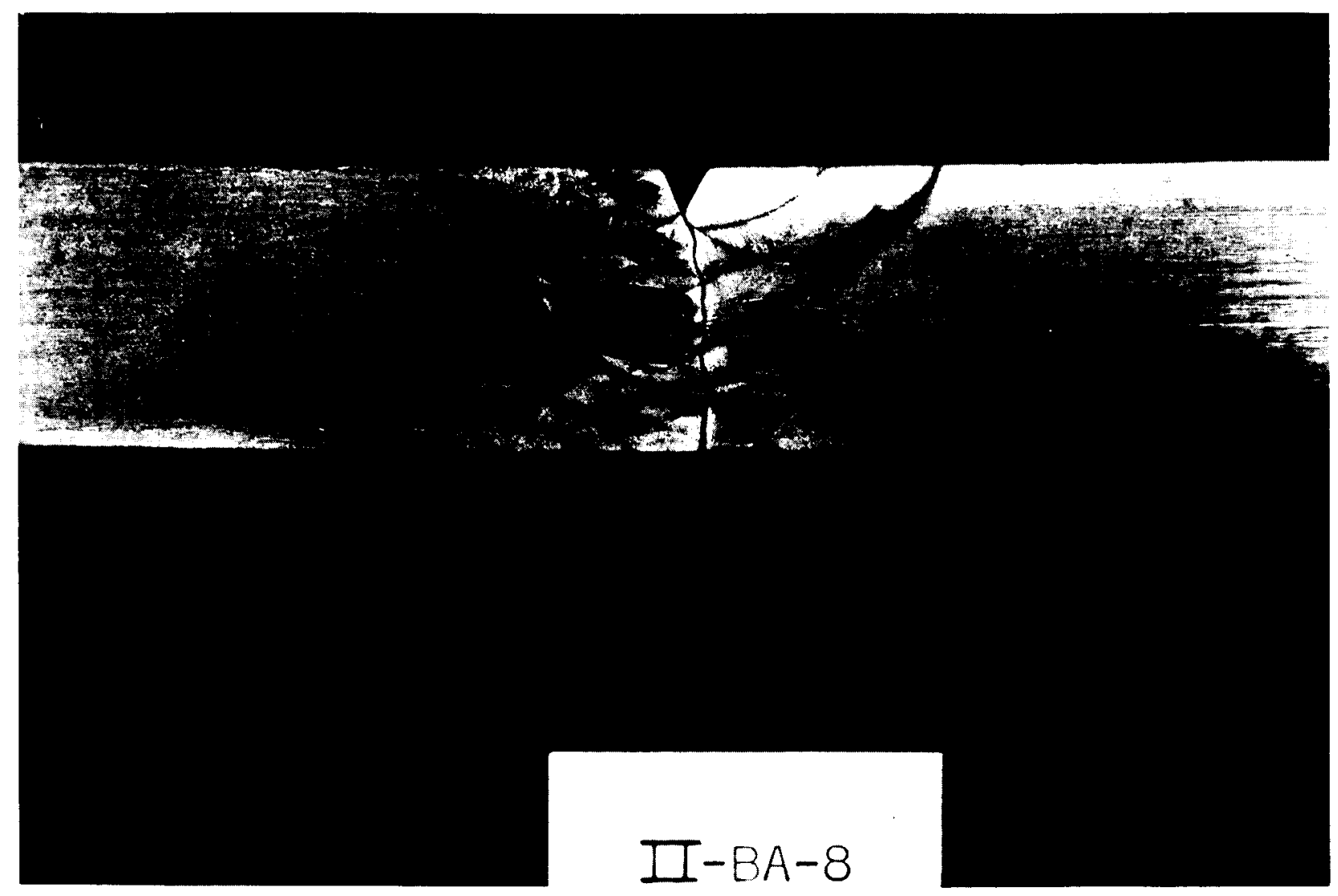

Figure 13b. 


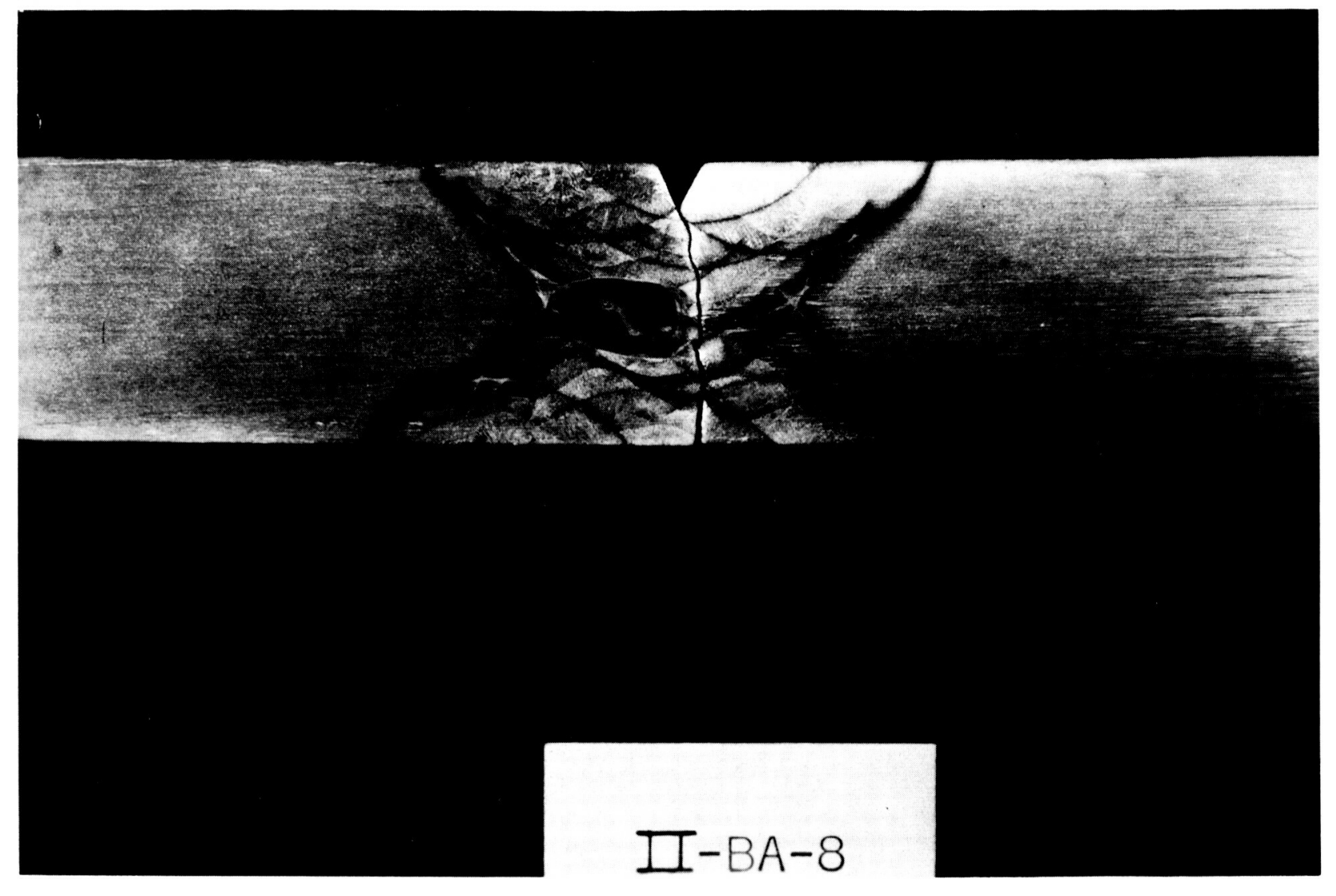

Figure 13b. 


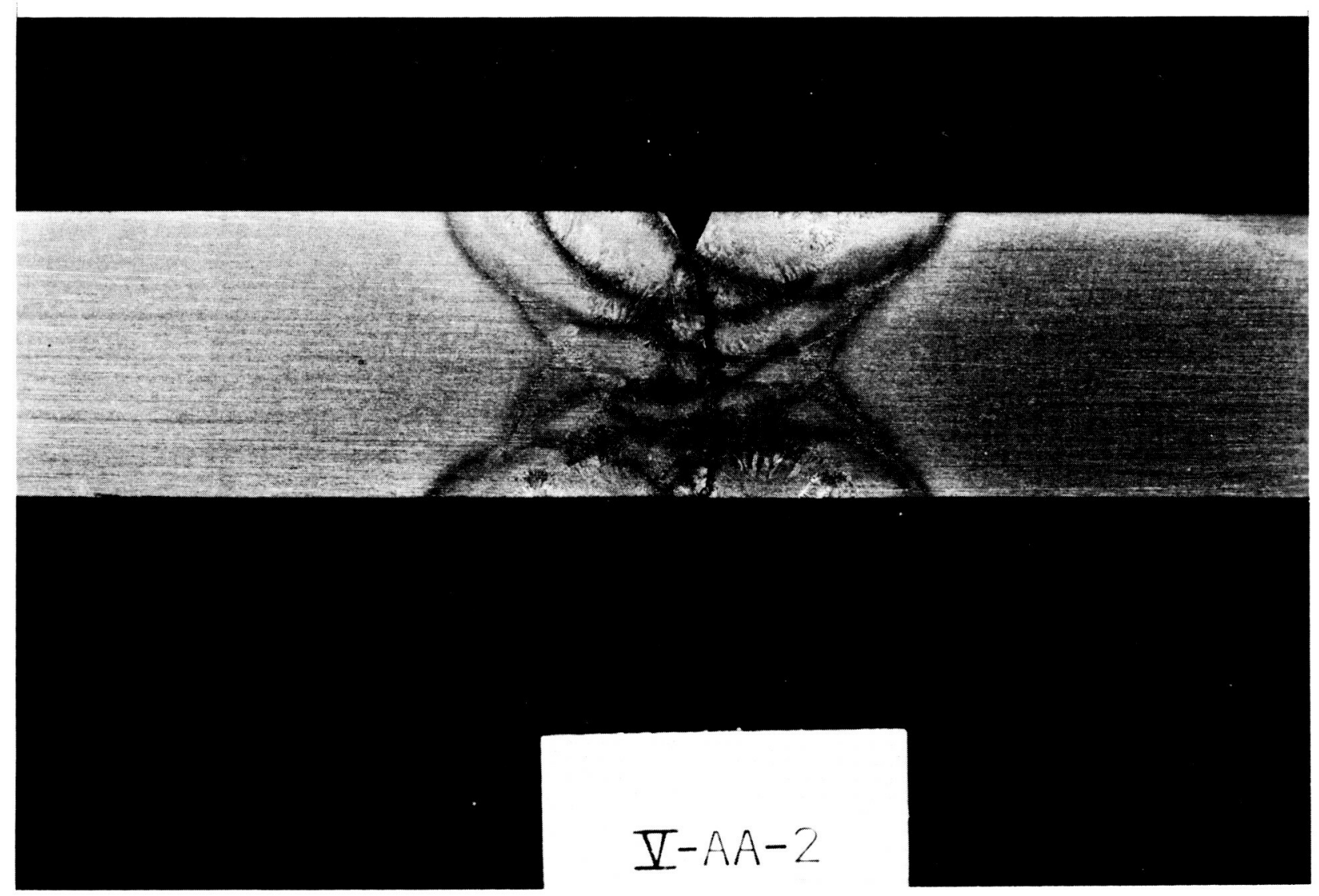

Figure $13 c$. 


\section{CODE: CW - CENTER OF WELD FUSION ZONE FZ - EDGE OF WELD FUSION ZONE HAZ- HEAT AFFECTED ZONE DB - DARK BAND AREA BM - BASE METAL}

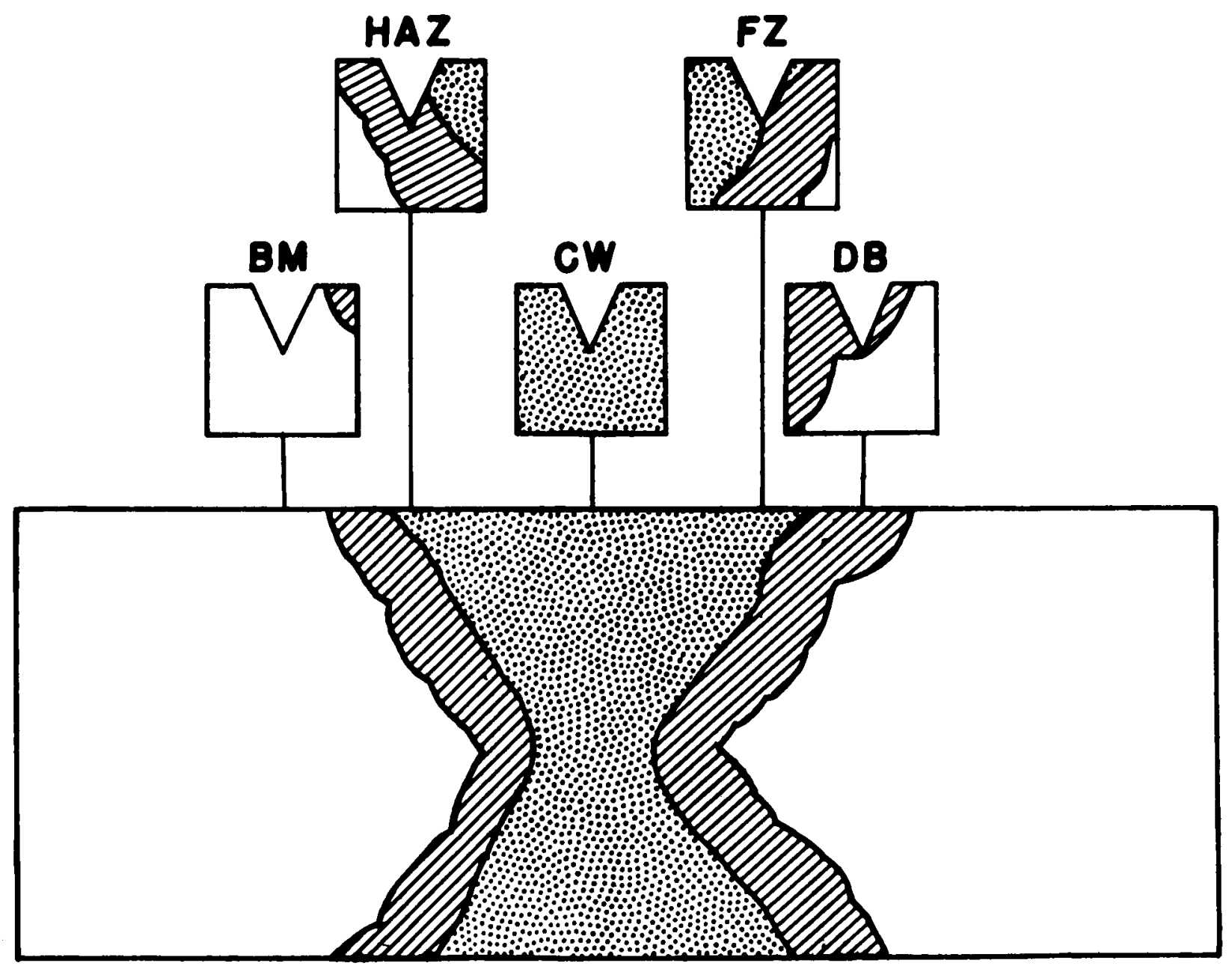

Figure 14.- Cross section of weld area showing different locations of starting notch tipped with fatigue crack. 


\section{APPENDIX \\ Fallure Analysis Example - Weld Flaw}

Figure Al shows an enlarged view of a fracture origin in a 156-inch diameter test chamber made of $\mathrm{H}-11$ steel. The prior crack was heat colored and presumably occurred during welding. It was sitwated at the edge of a longitudinal weld in the cylindrical section. At hydrotest fallure (early in 1964) the hoop stress was $77,000 \mathrm{ps} 1$. The prior crack was not a very perfect semfellipse and the bottom of the prior crack wes poorly delineated. The following data and conclusions illustrate a rather typical situation. Many similar hydrotest failures were encountered in the Polaris steel motor case development program.

$$
\begin{aligned}
& \text { Flaw depth } " a "=0.130+.020 \text { inch } \\
& -0 \\
& \text { Plate thickness } t=B=0.38 \text { inch } \\
& 2 c=I=\text { prior crack length at the surface } \\
& =0.500 \text { inch } \\
& \frac{a}{2 c}=0.260 \\
& \sigma_{\mathrm{YS}}=\text { uniaxial yield strength }=203,000 \mathrm{ps} \\
& \frac{\sigma_{\text {hoop }}}{\sigma_{\text {YS }}}=0.378 \\
& Q=\left[\Phi^{2}-.212\left(\frac{\sigma}{a_{Y S}}\right)^{2}\right]=1.45 \text { by the Tiffany chart. }
\end{aligned}
$$




$$
\begin{aligned}
& \mathrm{K}_{I_{c}}^{2}=\frac{3.77(77000)^{2}(0.13)}{1.45} \\
& K_{I c} \cong 45 \mathrm{Ks} 1 \sqrt{\operatorname{In}} .
\end{aligned}
$$

This is the Indicated value of $K_{I c}$ if instability or pop-in occurred at $" \mathrm{a} "=0.130$. This low value is not uncommon in and near welds in $\mathrm{H}-11$ steel of this thickness.

There is no proof that instablilty really occurred at $" \mathrm{a} "=0.130$. It is concelvable that some slow growth extended the crack deeper. If the slow extension had carried the crack all the way through the thickness, the length of the crack would have been $2 a_{c} \cong 1.0$ inch as judged from the photograph. Uncertalnty in this number seems to be $\pm 15 \%$ and is quite subjective. The fracture still contains almost no shear lip so that $K_{I c}$ is st1ll the determining toughness for possible arrest. For the through crack: -

$$
\begin{aligned}
& K_{I c}^{2}=\frac{\pi \sigma^{2} a_{c}}{1-0.5\left(\frac{\sigma}{\sigma_{Y S}}\right)^{2}} \\
& K_{I c} \cong 100 \mathrm{Ks1} \sqrt{\mathrm{In}} .
\end{aligned}
$$

Th1s is higher than we have reason to believe is characteristic of the material.

Conclusions:

1. Instability and hydrotest failure were completely determined before the surface crack had penetrated through the thickness.

2. The $K_{c}$ for $H-11$ could not tolerate a $2 t$ or $2 B$ crack even at 77,000 psi hoop stress for $t=B=0.38$ inch. 
3. The crack depth at instability seems to have been at the initial black walled prior crack border but this is not a matter of absolute certainty and depends on subjective judgement of the fracture appearance.

4. We did not have adequate data to predict the $K_{I c}$ or acrit. for such a crack. A considerable uncertainty in a crit. exists.

5. The important thing here is that the crack should have been detected and repaired. Failure prevention is better than fallure analysis.

NRL Chemical Analyses - Center of Weld

\begin{tabular}{|c|c|c|c|c|}
\hline \multirow[b]{2}{*}{ Element } & \multirow[b]{2}{*}{ Rod } & \multicolumn{2}{|c|}{ Center of Weld } & \multirow[b]{2}{*}{ TIG } \\
\hline & & Short Arc & MIG & \\
\hline C & 0.02 & 0.02 & 0.02 & 0.02 \\
\hline $\mathrm{Mn}$ & 0.03 & 0.03 & 0.03 & 0.03 \\
\hline $\mathbf{P}$ & 0.004 & 0.002 & 0.003 & 0.004 \\
\hline 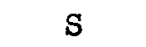 & 0.005 & 0.005 & 0.005 & 0.005 \\
\hline Si & 0.02 & 0.03 & 0.04 & 0.02 \\
\hline $\mathrm{N} 1$ & 18.24 & 18.2 & 18.0 & 18.0 \\
\hline Mo & 4.62 & 4.60 & 4.60 & 4.60 \\
\hline Co & $7 \cdot 90$ & $7 \cdot 79$ & 8.28 & 7.67 \\
\hline $\mathbf{T I}$ & 0.45 & 0.43 & 0.43 & 0.43 \\
\hline Al & 0.09 & 0.09 & 0.10 & 0.11 \\
\hline
\end{tabular}




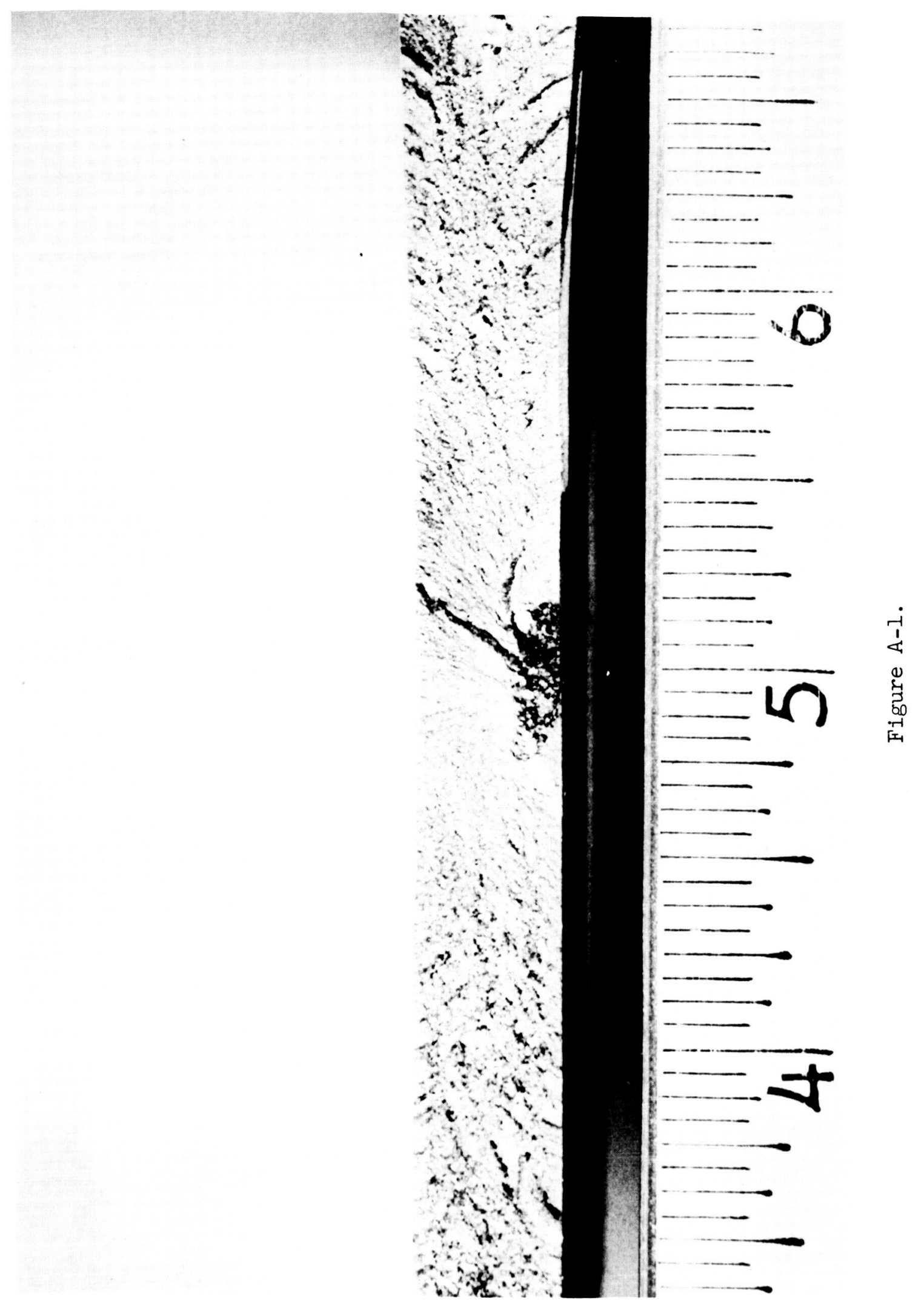


There are favorable points as well as objectionable points to each type of specimen whlch one might choose to use in making plane strain fracture toughness measurements. The application in mind will generally dictate one's cholce. For the work reported here, it was necessary to evaluate plates with a nominal thickness of $3 / 4 "$ since the application was the $260^{\prime \prime}$ solid booster motor case. Further the materlal to be evaluated was the $18 \%$ Nickel maraging steel which has been subject to a certain amount of banding. It was also desirable to study cracks propagating in the thickness direction (short transverse) as the more likely concern from a practical application standpoint. Because of the reasons listed here, our cholce of specimen was narrowed to either the partially through surface crack in tension or the notch bend test. It was decided that different areas of the weld could be better descriminated using the flat bottom notch of a bend bar rather than the curved perimeter of an elliptical surface notch. It would require from three to four times as much material for a surface notch specimen as that required for a bend specimen.

Three point loading rather than four point loading was selected largely because of convenience. The deflections for a given load are larger in three point loading requiring less magnification of strain measurements. Further one bend test setup is sufficient to test a wide range of specimen sizes in three point loading. 


\section{Use of $\mathrm{K}$ Values Computed from an Equation}

Difficulties not previously experienced were found in this investigation. The problem being austenfte segregation and carbide precipitates which result In varying amounts of banding throughout each plate. These variations result In an Indeterminate modulus, $E$. One could avold this difficulty by notching bend bars in the thickness direction. However, the resulting direction of crack propagation might be unrealistic in relation to the type of failure expected in an actual motor case.

If one measures the compliance, $C$, of a bend bar as a function of notch depth, the ratio of load to deflection, at the point of interest, determines the effective notch depth for use in calculating $\$$. However, one must know $E$ in order to relate load to crack size. If $E$ is indeterminate the relation of load to crack size is indeterminate. For this reason it was found convenient to represent $\mathrm{EC}$ as a function of relative crack depth in equation form and to use this representation and a visual determination of critical notch depth. The resulting $K$ values may scatter and be somewhat altered due to delaminations, but such a procedure establishes a $K$ value for each test which represents a relationship between load and notch depth independent of modulus. Such values are belleved to be more useful than the values. 